\title{
Microscopic Pore Structure Characteristics and Methane Adsorption of Vitrain and Durain
}

\author{
Fu Yang, ${ }^{1,2,3}$ Dongmin Ma, ${ }^{1,3}$ Zhonghui Duan, ${ }^{1,2}$ Dazhong Ren, ${ }^{1,4}$ Tao Tian,,2 \\ and Dengke Liu $\mathbb{D}^{1,5}$ \\ ${ }^{1}$ Key Lab of Coal Resources Exploration and Comprehensive Utilization Ministry of Nature Resources, Xi'an 710021, China \\ ${ }^{2}$ Shaanxi Coal Geology Group Co., Ltd., Xi'an 710021, China \\ ${ }^{3} X i$ 'an University of Science and Technology, Xi'an 710054, China \\ ${ }^{4} X i$ 'an Shiyou University, Xi'an 710065, China \\ ${ }^{5}$ School of Human Settlement and Civil Engineering, Xi'an Jiaotong University, Xi'an 710049, China
}

Correspondence should be addressed to Dengke Liu; liudengke02@126.com

Received 24 August 2020; Revised 29 September 2020; Accepted 16 October 2020; Published 23 November 2020

Academic Editor: Shiyuan Zhan

Copyright $(2020 \mathrm{Fu}$ Yang et al. This is an open access article distributed under the Creative Commons Attribution License, which permits unrestricted use, distribution, and reproduction in any medium, provided the original work is properly cited.

\begin{abstract}
During reservoir evaluation, the microscopic pore structure of low-rank coal is mainly characterized in order to study the coalbed methane diffuse and migration mechanisms and control. The low-rank coals are very different in pore type and size, so it is necessary to use various techniques to describe their pore structure. For vitrain and durain of the Coal Member of the Yan'an Formation from Huanglong Coalfield, their chemical composition and microscopic pore structure characteristics were studied, and the factors of influencing the pore size distribution (PSD) were explored. Obviously, vitrain and durain are different in chemical composition. Vitrain has higher moisture content, volatile yield, and vitrinite group content than durain. Vitrain and durain mainly contain vitrinite and inertinite, respectively. The pore structure characteristics (e.g., pore types and PSD) of vitrain and durain were systematically by mercury intrusion porosimetry (MIP), low-temperature nitrogen adsorption, and carbon dioxide (CO2) adsorption. The vitrain and durain samples with a micropore size of $<2 \mathrm{~nm}$ were mainly tested on their specific surface area (SSA) and pore volume (PV). The results show that microporous vitrain has larger SSA and PV than microporous durain, while mesoporous and macroporous vitrain has smaller SSA and PV than mesoporous and macroporous durain. SSA is very positively correlated with PV. The ash content is negatively correlated with SSA and PV. The ash content influences microporous vitrain more greatly than microporous durain, but mesoporous and macroporous durain more greatly than mesoporous and macroporous vitrain. SSA is positively correlated with the vitrinite content of durain and negatively correlated with the inertinite and exinite contents of durain. However, SSA is negatively correlated with the vitrinite and exinite contents of vitrain and positively correlated with the inertinite content of vitrain. Vitrain has higher methane adsorption capacity, desorption rate, and recovery ratio than durain. There are parameters that are obviously affected by the micropore characteristics.
\end{abstract}

\section{Introduction}

Coalbed methane (CBM) resource is abundant in China. For the coalbed methane with a buried depth of less than $2000 \mathrm{~m}$, its geological resource and recoverable resources are $30 \times 10^{12} \mathrm{~m}^{3}$ and $12.5 \times 10^{12} \mathrm{~m}^{3}$, respectively. The low-rank coalbed methane resource accounts for $47 \%$ of total resources. Two coalbed methane industrial bases, which are located in the Qinshui Basin and the eastern margin of Ordos Basin, have been successfully operated. In spite of a break- through in low-rank coalbed methane development, lowrank coalbed methane has not been industrially produced yet. The microscopic pore structures of coals not only control the adsorption/desorption seepage and diffusion processes of coalbed methane but also affect the extraction efficiency of coalbed methane.

The microscopic pore structure of coal significantly influences the adsorption/desorption, seepage, and diffusion processes of coalbed methane. In this paper, the microscopic pore structure characteristics of coal, including pore cavity 


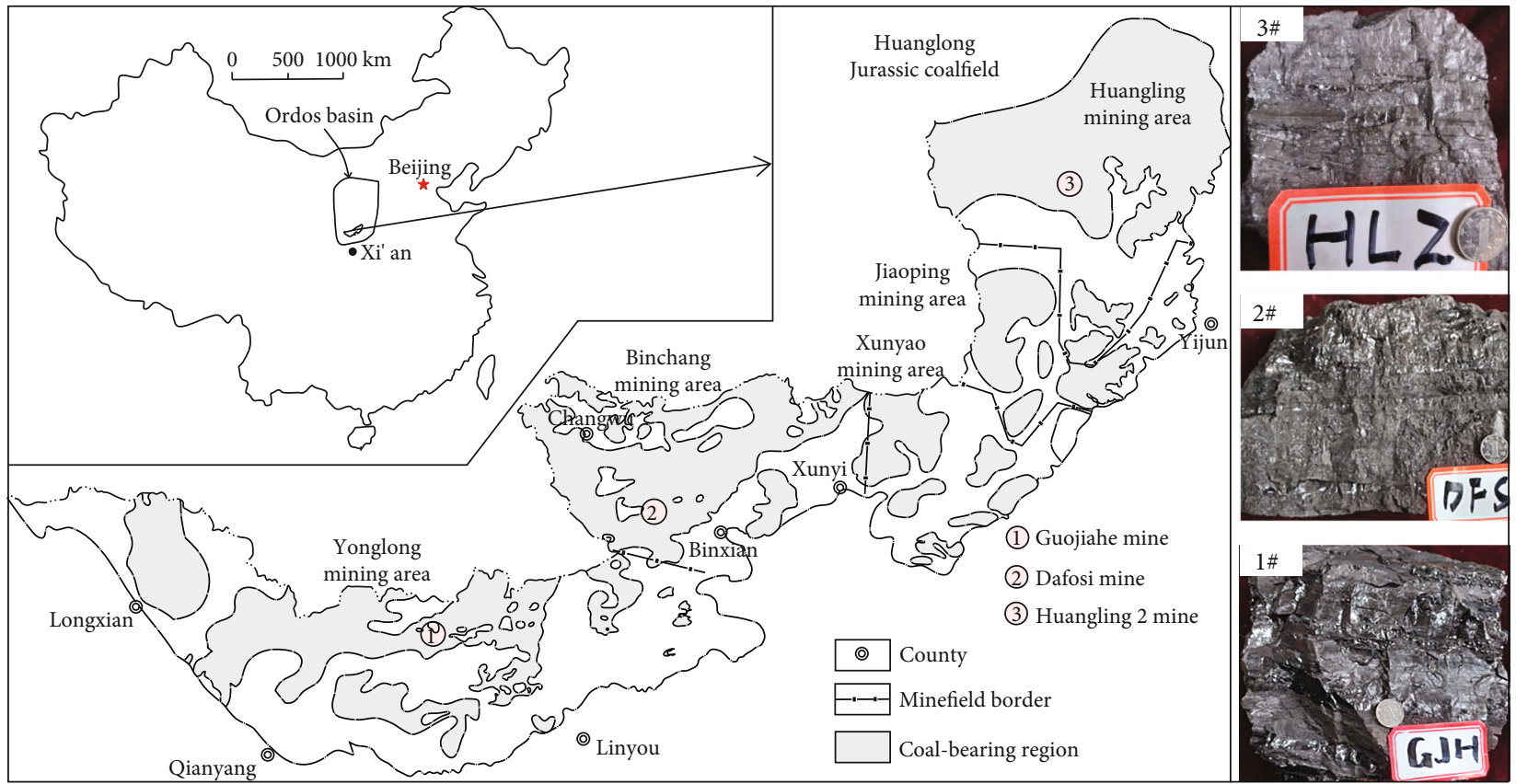

Figure 1: The distribution of the selected samples in the Southern Ordos Basin.

and throat size distribution and geometry, pore volume aperture and SSA, pore mineral filling and distribution, and coal seam skeleton particle size and distribution, were mainly studied by image observation and fluid injection. The pore fractures were observed and quantified by scanning electron microscopy (SEM), atomic force microscopy (AFM), transmission electron microscopy (TEM), high-resolution field emission scanning electron microscopy (FE-SEM), and focused ion beam scanning electron microscopy (FIB-SEM) [1-3]. Fluid injection methods include mercury injection, gas adsorption $\left(\mathrm{N}_{2}\right.$ and $\left.\mathrm{CO}_{2}\right)$, low field nuclear magnetic resonance (NMR), and small-angle scattering (SAS). Mercury injection method has unique advantages in the measurement of large and medium pores. The radius of the hole can be measured in the range of $3.75-750 \mathrm{~nm}$. According to the characteristics of mercury inlet and mercury ejection curves, the coal pore structure can be determined, but the information of nanoscale micropores and closed pores cannot be reflected, and the sample is damaged seriously [4]. In the gas adsorption method, the measuring range of pore size depends on the molecule size of the injected gas. The liquid nitrogen adsorption method and the $\mathrm{CO}_{2}$ adsorption method have a pore diameter measuring range of $0.4 \sim 2.0 \mathrm{~nm}$ and $0.35 \mathrm{~nm}$, respectively [5]. The pore distribution volume and SSA were calculated by different interpretation models [6]. A relatively complete capillary pressure curve and PSD were obtained by mercury injection, liquid nitrogen adsorption, and determination of microscopic pore structure [7-9]. The PSD connectivity and the proportion of movable fluid were obtained by NMR at different scales, with measuring accuracy from $8 \mathrm{~nm}$ to $80 \mu \mathrm{m}$, so the NMR method is feasible and effective for the medium-large pore structure of coal $[10,11]$. The pore structure distribution at a diameter of $1 \mathrm{~nm} \sim 20 \mu \mathrm{m}$ was obtained by a small-angle X-ray scattering method [12]. It is different in measurement principle and very different in pore SSA from the gas adsorption method [13]. A

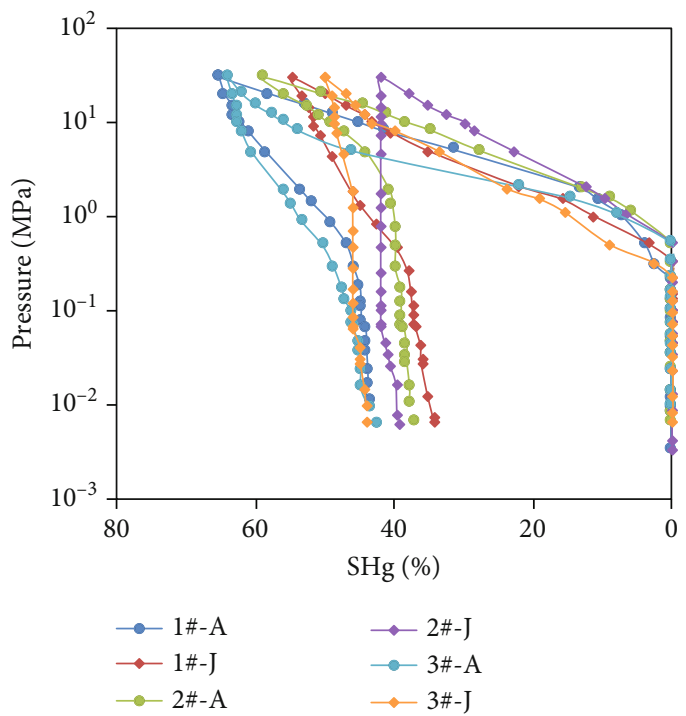

FIgURE 2: The mercury injection curves of vitrain and durain.

lot of researchers have studied how to characterize the pore structures of coal, but to the best knowledge of the authors, few researchers have studied the pore structure characteristics of the coals with different lithotypes in detail [14-16].

According to the pore classification standard of IUPAC, macropore, mesopore, and micropore are defined as a pore with a size above $50 \mathrm{~nm}$, between $2-50 \mathrm{~nm}$, and below $2 \mathrm{~nm}$, respectively. For the samples from Yan'an Formation in Huanglong Jurassic Coalfield, their PSD was studied in this paper. The vitrain and durain samples were collected and separated by hand in the mine before their chemical compositions were studied by industrial analysis and maceral identification. Their pore structure characteristics were studied by mercury injection, liquid nitrogen adsorption, and carbon 


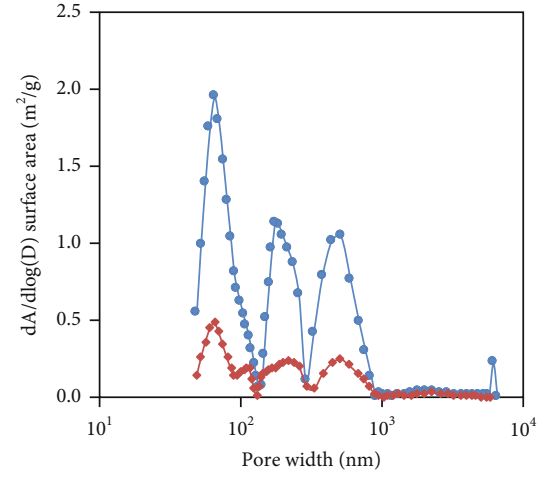

$\longrightarrow 1$ 1\#-A
$\longrightarrow 1$-J

(a)

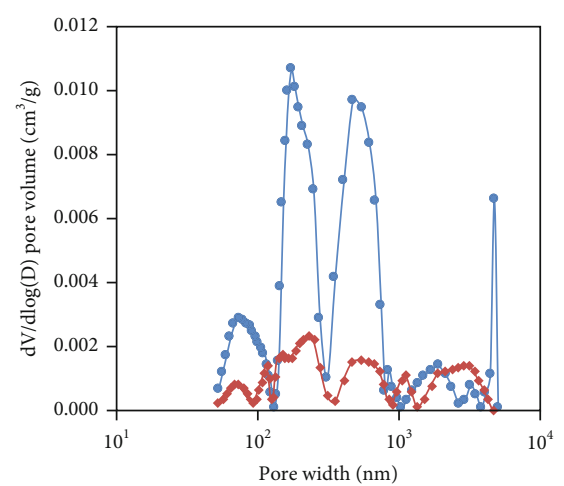

$\longrightarrow 1 \#-A$

$\rightarrow 1 \#-J$

(d)

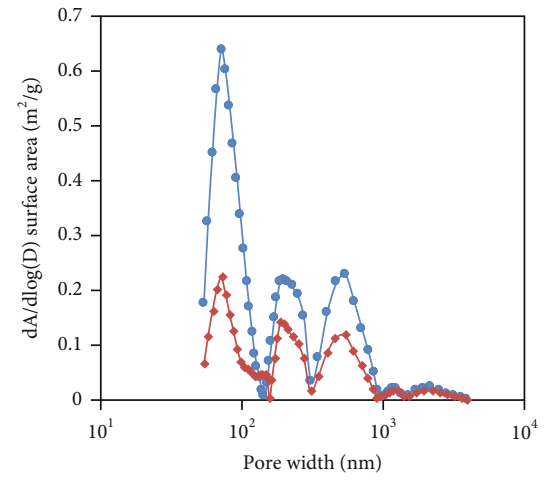

$\longrightarrow 2 \#-\mathrm{A}$

$\longrightarrow 2 \#-J$

(b)

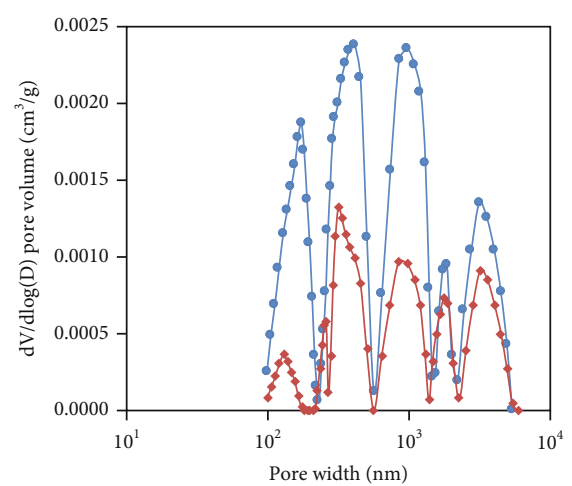

$\rightarrow 2 \#-A$

$\rightarrow 2 \#-\mathrm{J}$

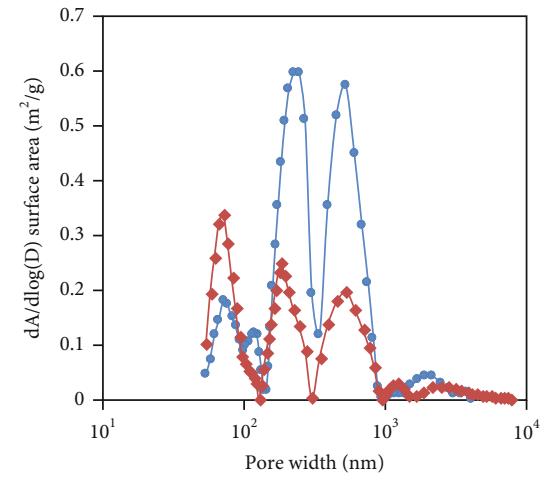

$\longrightarrow 3 \#-\mathrm{A}$

$\rightarrow 3 \#-\mathrm{J}$

(c)

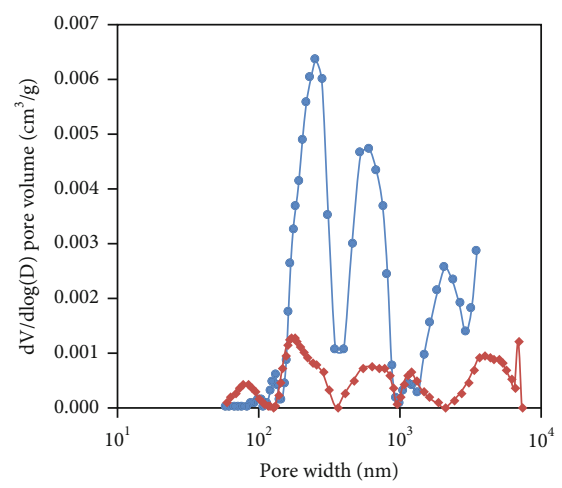

$\longrightarrow 3 \#-A$

$\rightarrow 3 \#-J$

(f)

FIGURE 3: PSD is calculated according to the mercury intrusion data of vitrain and durain.

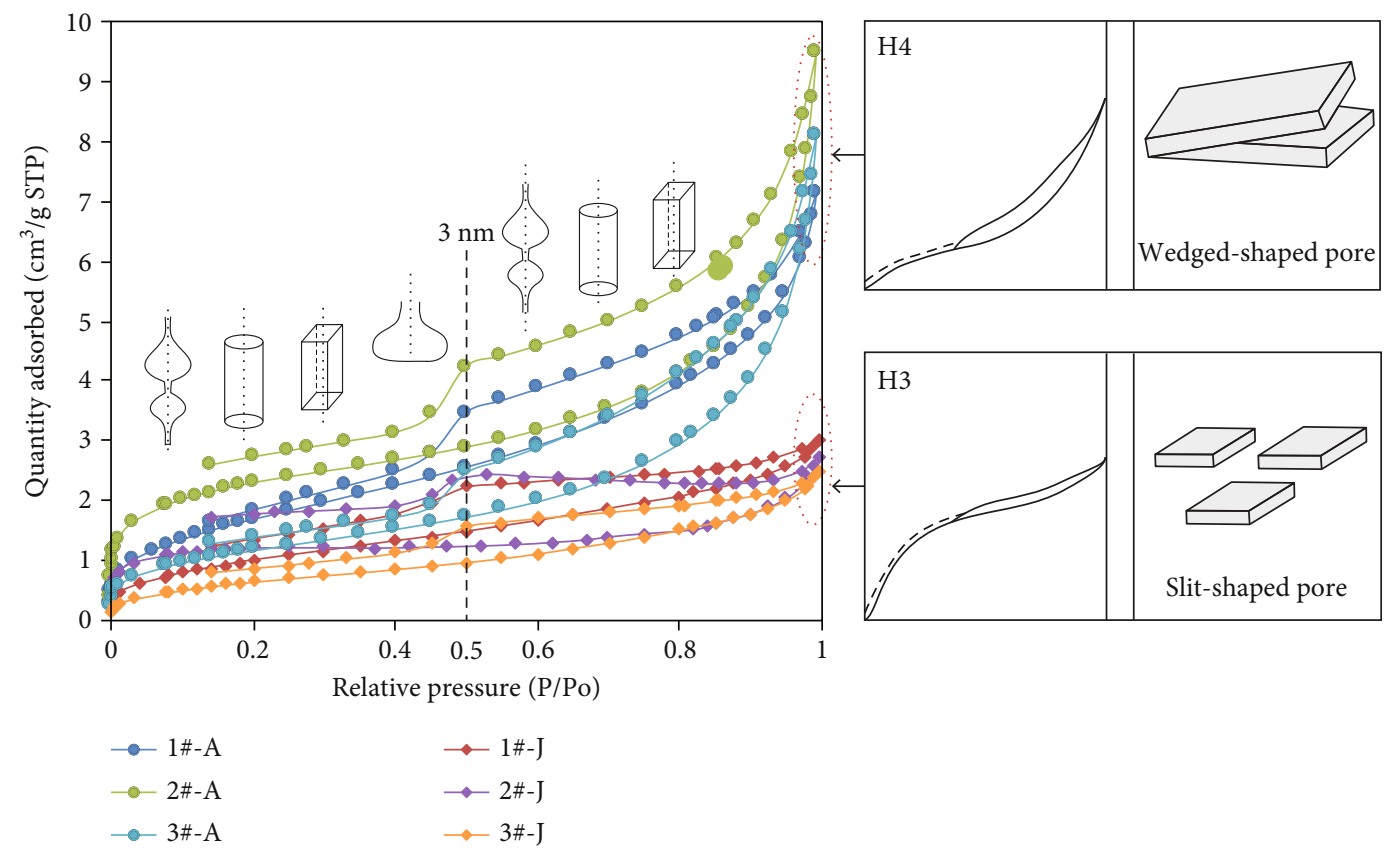

FIGURE 4: Ad/desorption isotherms of the $\mathrm{N}_{2}$ adsorption test of vitrain and durain. 

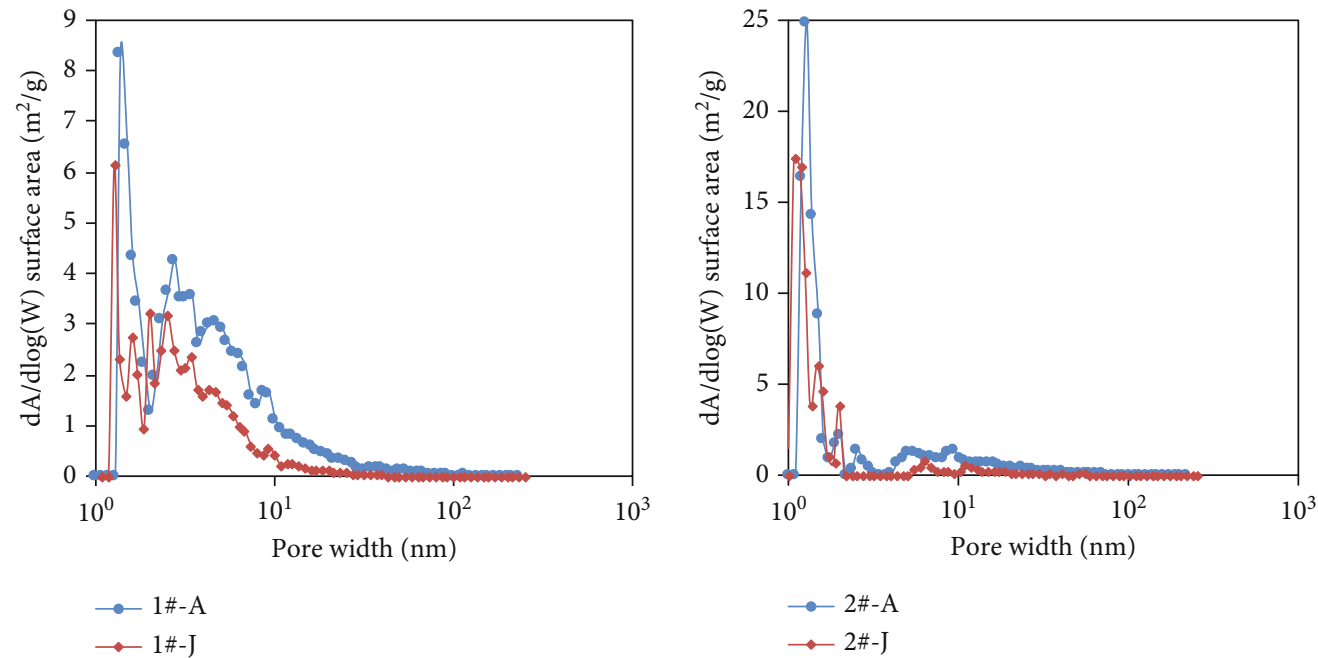

(a)
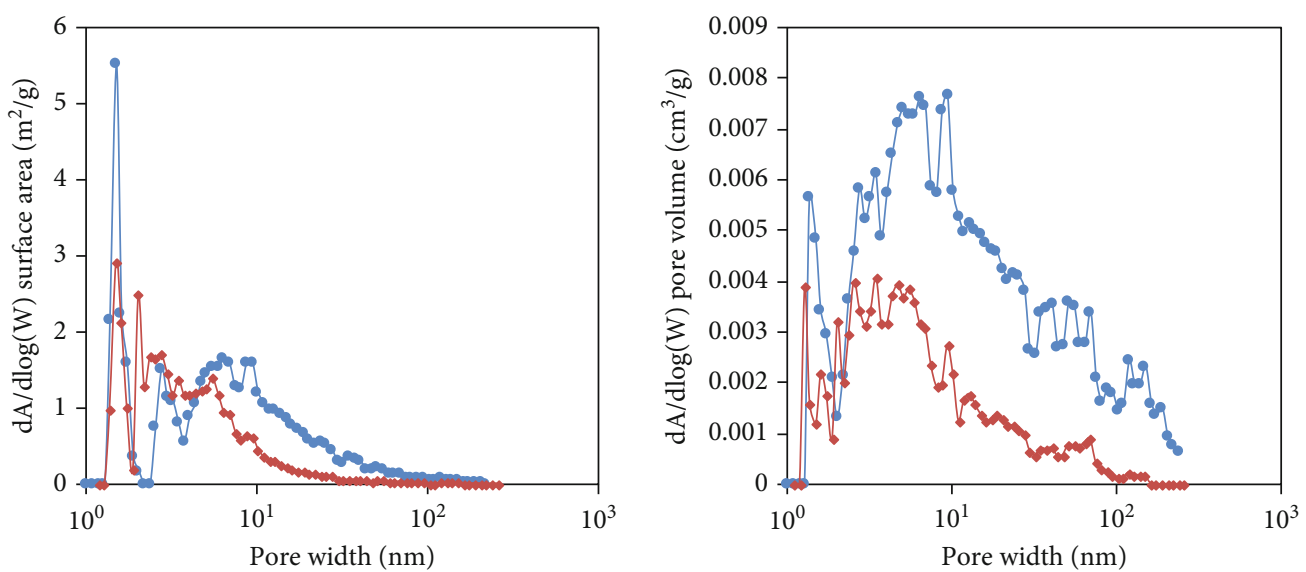

$\rightarrow 3 \#-A$

$\rightarrow 1 \#-A$

$\rightarrow 1$ -

(c)

(d)
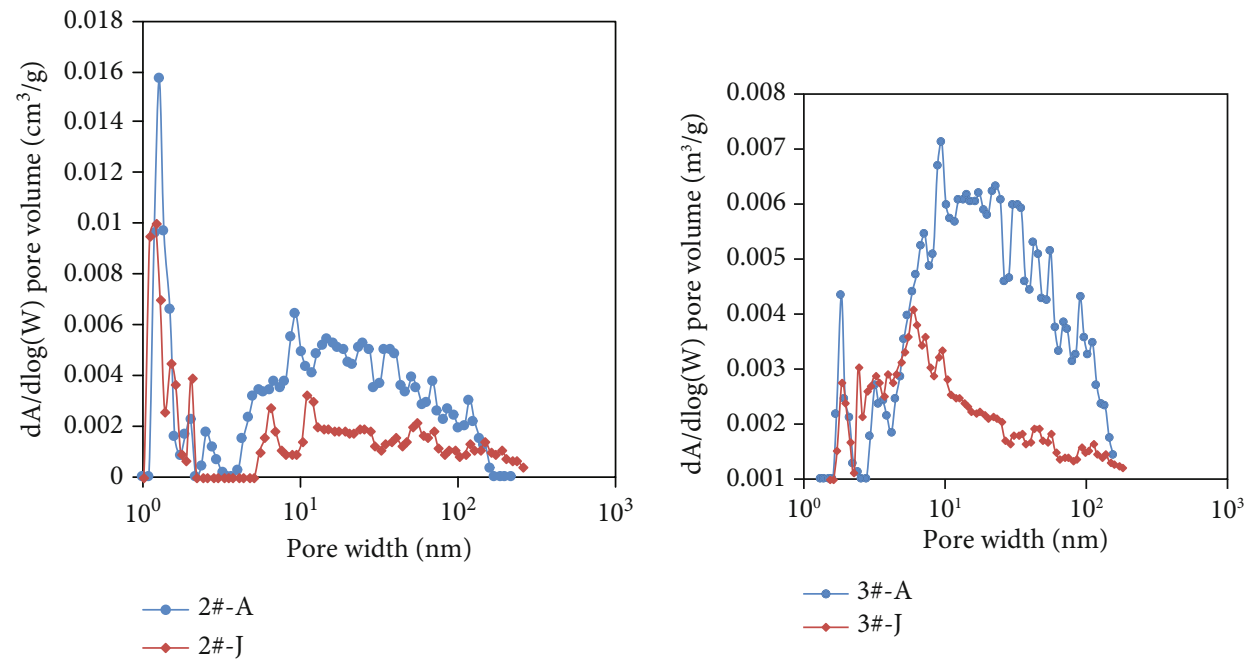

(e)

(f)

FIGURE 5: PSD is calculated according to the liquid $\mathrm{N}_{2}$ adsorption data of vitrain and durain. 
dioxide adsorption. The differences in pore structure between vitrain and durain, the influencing factors, and the effect of pore structure on methane desorption were discussed.

\section{Sample and Experiment}

2.1. Sample Description and Preparation. Six samples from three mines in the Yan'an Formation of the Huanglong Jurassic Coalfield were used to study their microstructures. The sampling sites in the study area are shown in Figure 1.

Sample 1\#, which was collected from No. 2 main coal seam of the Guojiahe Mine in the Yonglong Mine Field, mainly contains semidark coal and semibright coal with macrolithotype.

Sample 2\#, which was collected from No. 4 main coal seam of Dafosi Mine in the Binchang Mine Field, contains a lot of dull coal, semidark coal, and a small amount of semibright coal with macrolithotype.

Sample 3\#, which was collected from No. 2 main coal seam of Huangling 2 Mine in Huangling Mine Field, mainly contains semidark coal and minorly semibright coal with macrolithotype.

The aforementioned coal samples were separated by hand to obtain six samples, including three vitrain samples and three durain samples, for this study.

2.2. Experimental Method. The six samples were studied by proximate analysis, maceral analysis, vitrinite reflectance $\left(R_{\mathrm{O}}\right)$, scanning electron microscopy (SEM) analysis, mercury intrusion analysis, low-temperature $\mathrm{N}_{2}$, and $\mathrm{CO}_{2}$ gas adsorption (Table S1) in the Key Lab of Coal Resources Exploration and Comprehensive Utilization, Ministry of Natural Resources, China.

\section{Results}

3.1. Geochemical Composition. The results of the proximate analysis and maceral analysis are shown in Table S2. The three vitrain samples have lower ash content $\left(A_{d}\right)$ and higher volatile content $\left(V_{\mathrm{ad}}\right)$ than the three durain samples.

Vitrain mainly contains vitrinite group, while durain mainly contains inertinite.

3.2. Mercury Intrusion Porosimetry. Mercury Intrusion Porosimetry (MIP) is more favorable for the measurement of macropores $(>50 \mathrm{~nm})$. The pore size was calculated according to Equation (1) proposed by Washburn (1921).

$$
d=\frac{-4 \gamma \cos \theta}{p}
$$

The SSA was calculated according to Equation (2) proposed by Rootare and Prenzlow (1967).

$$
S=\frac{1}{\gamma \cos \theta} \int_{0}^{V} p d v
$$

where $d$ is the pore diameter (nm); $P$ is the applied pressure, $\mathrm{MPa} ; \gamma$ is the surface tension of mercury; $\theta$ is the contact

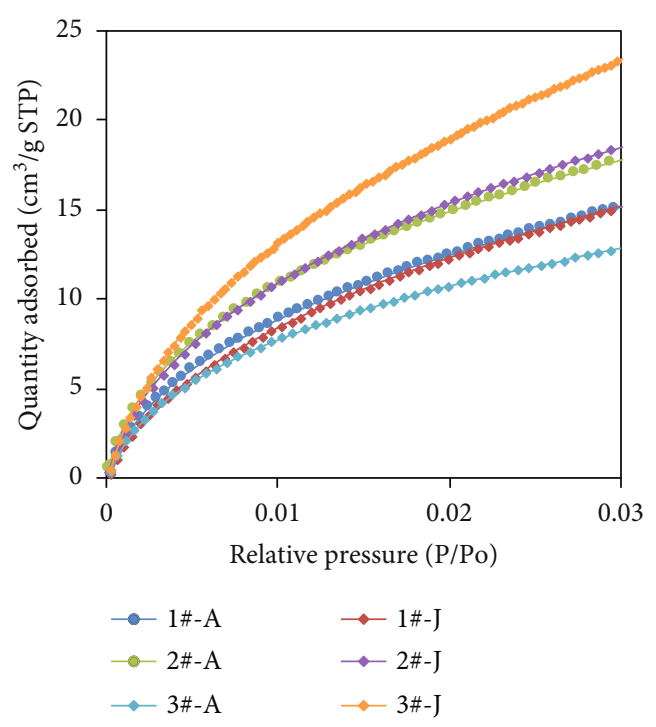

FIGURE 6: The $\mathrm{CO}_{2}$ adsorption isotherm of vitrain and durain.

angle between mercury and the solid surface; $S$ is specific surface area, $\mathrm{m}^{2} / \mathrm{g} ; V$ is the amount of mercury input, $\mathrm{cm}^{3} / \mathrm{g}$. The values of $\gamma$ and $\theta$ are $0.480 \mathrm{~N} / \mathrm{m}$ and $140^{\circ}$, respectively [17].

The parameters of pore structure measured by mercury injection are shown in Table S3. Both vitrain and durain have small displacement pressure $\left(P_{d}\right)$, indicating that they have good pore permeability. Vitrain has a larger average throat radius $(R)$ than durain. Both vitrain and durain have the skewness $\left(S_{k}\right)$ of greater than 1 , indicating the thicker pore throat. Vitrain has a much bigger structural coefficient $(\varphi)$ than durain, indicating the intense circumfluence of pore bending. Both vitrain and durain have a small sorting coefficient of throats $\left(S_{p}\right)$, reflecting the uniform pore distribution. Durain has bigger mercury saturation $\left(S_{\mathrm{Hg}}\right)$ than vitrain and exhibits a large lag space in the mercury curve. It is concluded that durain has better pore connectivity than vitrain. Durain mainly has open pores, while vitrain may have semiclosed pores. Vitrain has smaller SSA and pore volume than durain.

The mercury injection curves of the samples are shown in Figure 2. The difference in mercury saturation indicates that the coals mainly have open pores. The coal samples have low mercury removal efficiency, indicating that the coals have a large number of fine bottleneck pores.

The PSD values of samples obtained by mercury intrusion test are shown in Figure 3 consisting of dV/d $(\log D)$ curves and $\mathrm{dA} / \mathrm{d}(\log \mathrm{D})$ curves. The $\mathrm{dV} / \mathrm{d}(\log \mathrm{D})$ and $\mathrm{dA} / \mathrm{d}(\log \mathrm{D})$ are calculated from the measured cumulative pore volume and SSA. The curves of $\mathrm{dV} / \mathrm{d}(\log \mathrm{D}), \mathrm{dA} / \mathrm{d}(\log \mathrm{D})$ versus pore width perfectly reflect PSD [18]. The PSD values of the samples used in the MIP are mainly $>50 \mathrm{~nm}$. The PSD values of more than $1 \mu \mathrm{m}$ also were identified in all samples. Durain has higher $\mathrm{dV} / \mathrm{d}(\log \mathrm{D})$ and $\mathrm{dA} / \mathrm{d}(\log \mathrm{D})$ value than vitrain, suggesting that durain has bigger PVs and SSAs bigger than vitrain.

3.3. Liquid $\mathrm{N}_{2}$ Physisorption. It is believed that the nitrogen adsorption method is suitable for mesopores $(2-50 \mathrm{~nm})$. The pore size and SSA were mainly calculated according to 

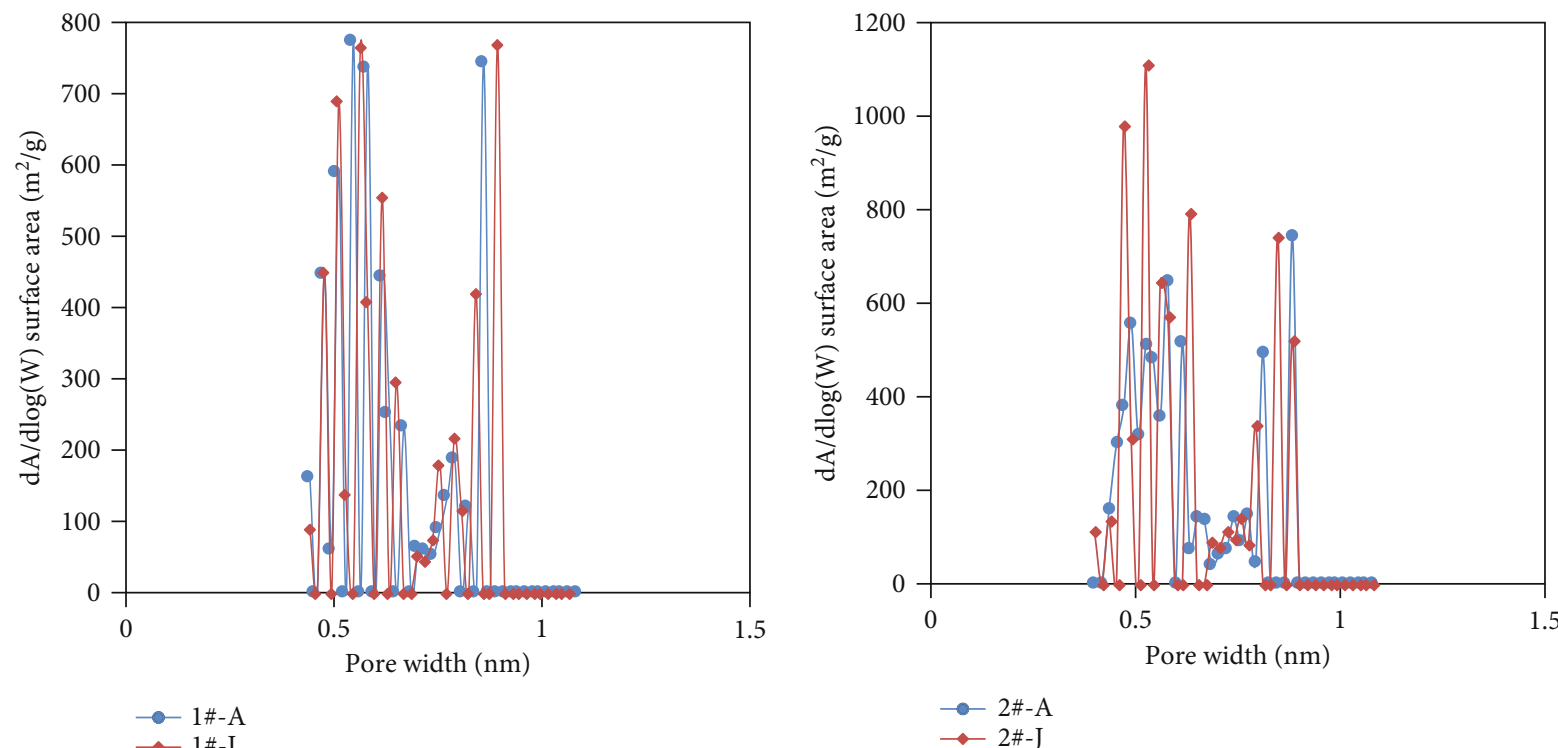

(a)

(b)
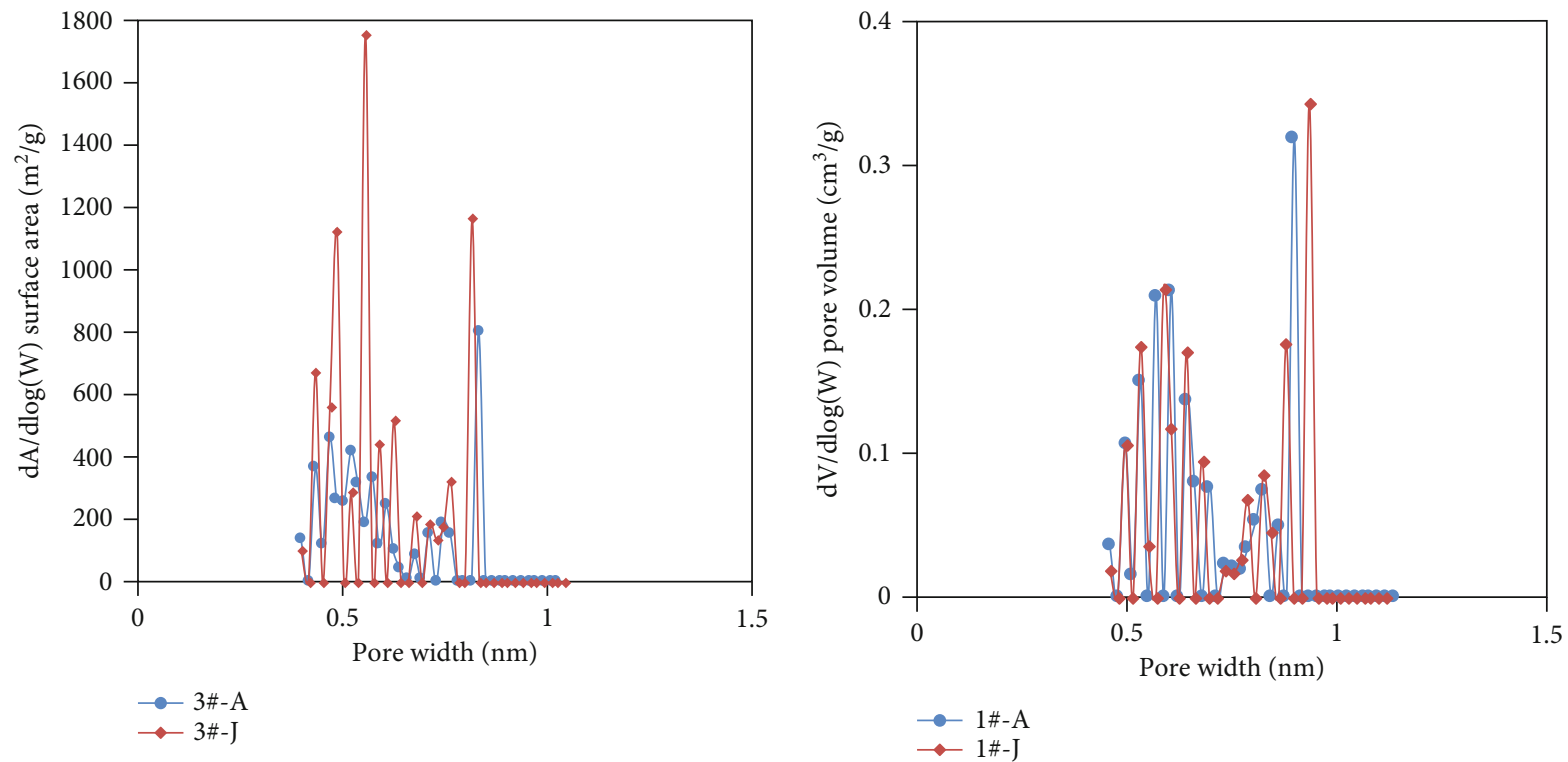

(c)

(d)

Figure 7: Continued. 


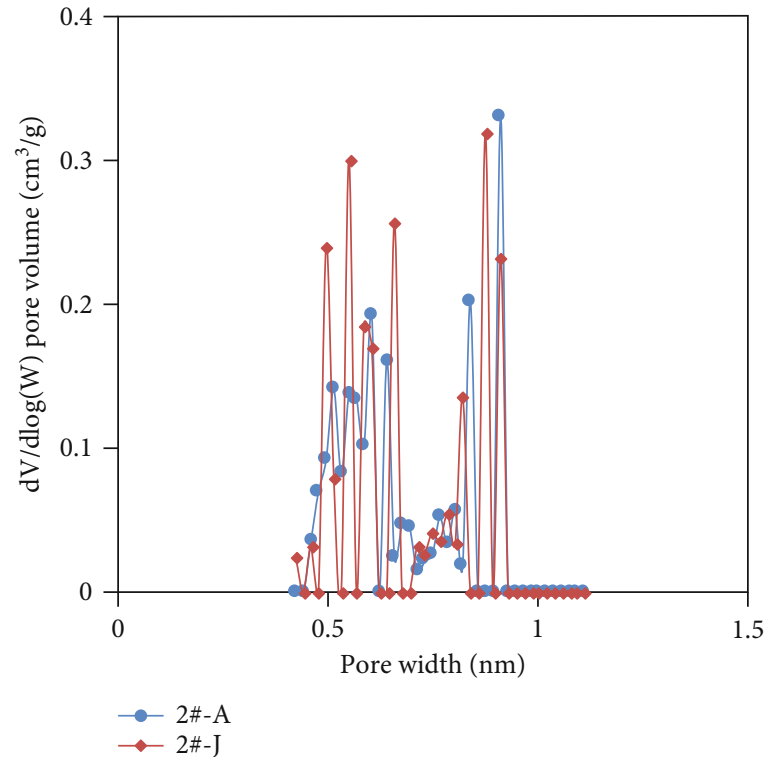

(e)

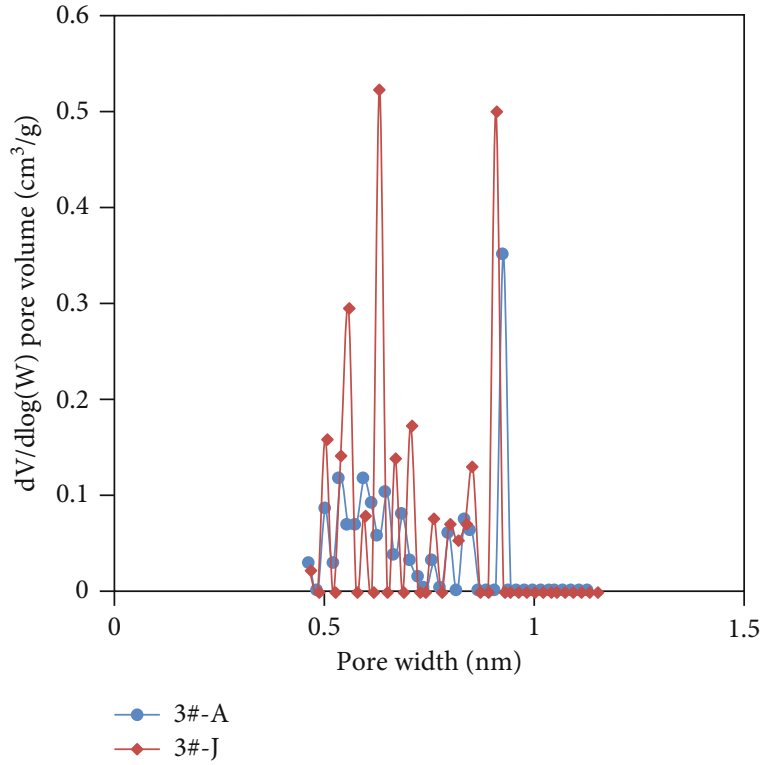

(f)

FIGURE 7: PSD is calculated according to the $\mathrm{CO}_{2}$ adsorption data of vitrain and durain.

the results of $\mathrm{N}_{2}$ adsorption experiments by BJH, BET, and DFT models. The technical report of IUPAC in 2015 shows that the Kelvin equation (BJH method) is used to calculate the SSA of the plate pores with the diameter $<10 \mathrm{~nm}$, but the calculated result is underestimated by $20 \% \sim 30 \%$. The molecular model and DFT method effectively avoid the errors caused by Kelvin equation-based calculation and have higher calculation accuracy than the classical BET method [6]. The PV and SSA results are shown in Table S3. Durain has a larger pore size, SSA, and PV than vitrain, indicating that durain has a higher adsorption capacity than vitrain (Table S3). The PV mainly distributes in mesopores. For the samples $1 \#$ and 3\#, SSA mainly distributes in mesopores. For the sample 2\#, SSA mainly distributes in micropores.

The nitrogen adsorption-desorption curve of coal can be used to analyze the pore structure characteristics [19]. $\mathrm{N}_{2}$ adsorption curves of coal samples are shown in Figure 4. The recommended physisorption isotherms of IUPAC in 2015 were divided into eight types. In this paper, the vitrain and durain samples have the adsorption behaviors closer to Types I and IV(a) adsorption curves; the adsorption content sharply increases at a low relative range $(\mathrm{P} / \mathrm{P} 0=0-0.1)$ because of micropore filling effect, indicating that the rocks contain micropores (Type I); and the curve exhibits a hysteresis loop at high relative pressures $(\mathrm{P} / \mathrm{Po}>0.45)$, indicating the multilayer range is associated with capillary condensation in mesopores (Type IV) [20] and then behaves like multilayer sorption and capillary condensation at higher pressure $(\mathrm{P} / \mathrm{P} 0=0.8-1)$, suggesting the existence of both mesopores and macropores in the samples $[6,21,22]$. The adsorptiondesorption curves of all the samples are not completely closed in the low-pressure hysteresis loop (Figure 4) due to filling or adsorption in micropores, as considered by many researchers [23]. These samples have an inflection point, at which the desorption curve sharply drops at the relative pressure $\left(\mathrm{P} / \mathrm{P}_{0}\right)$ of 0.5 , indicating the existence of slit-shaped pores or ink-bottle-shaped pores [20,24]. The relative pressure at the inflection point calculated according to the Kelvin equation corresponds to a pore size of about $3 \mathrm{~nm}$, indicating that the pores with the pore size $<3 \mathrm{~nm}$ have one closed end.

The PSD values of the samples obtained from the Liquid $\mathrm{N}_{2}$ adsorption test are shown in Figure 5 consisting of $\mathrm{dV} / \mathrm{d}$ $(\log \mathrm{W})$ curves and $\mathrm{dA} / \mathrm{d}(\log \mathrm{W})$ curves. Figures $5(\mathrm{a})-5(\mathrm{c})$ show that SSA mainly increases in the micropores $(<2 \mathrm{~nm})$, and durain has higher increment of SSA than vitrain. Figures $5(\mathrm{~d})-5(\mathrm{f})$ consisting of the curves of $\mathrm{dV} / \mathrm{d}(\log \mathrm{W})$ vs. pore width show the PV increment distribution characteristics. The samples 1\# and 3\# have consistent PV distribution curves and have mesopores and macropores. For the sample 2\#, the PV mainly distributes in micropores. Durain has higher $\mathrm{dV} / \mathrm{d}(\log \mathrm{W})$ and $\mathrm{dA} / \mathrm{d}(\log \mathrm{W})$ values than vitrain, suggesting that durain has bigger PVs and SSAs than vitrain. This result is consistent with that from the mercury injection test.

3.4. $\mathrm{CO}_{2}$ Physisorption. Low-pressure adsorption (LPA) of $\mathrm{CO}_{2}$ is a powerful tool to calculate PSD, SSA, and PV of the pores with a size of $0.3-1.5 \mathrm{~nm}$ [25]. Table S4 lists the micropore size of $0.6330-0.6619 \mathrm{~nm}$, PV of $0.01846-$ $0.02609 \mathrm{~cm}^{3} / \mathrm{g}$, and SSA of $102.898-195.631 \mathrm{~m}^{2} / \mathrm{g}$ obtained from the $\mathrm{CO}_{2}$ adsorption test by DFT model. The above results show that vitrain has a bigger micropore size, PV, and SSA than durain.

The $\mathrm{CO}_{2}$ adsorption isotherm and PSD of micropores are shown in Figures 6 and 7, respectively. The $\mathrm{CO}_{2}$ adsorption isotherms of the durain and vitrain samples are similar to the Langmuir curve (Figure 6). The curves go upward at low pressure $(\mathrm{P} / \mathrm{P} 0<0.01)$ and tend to be linear at high 


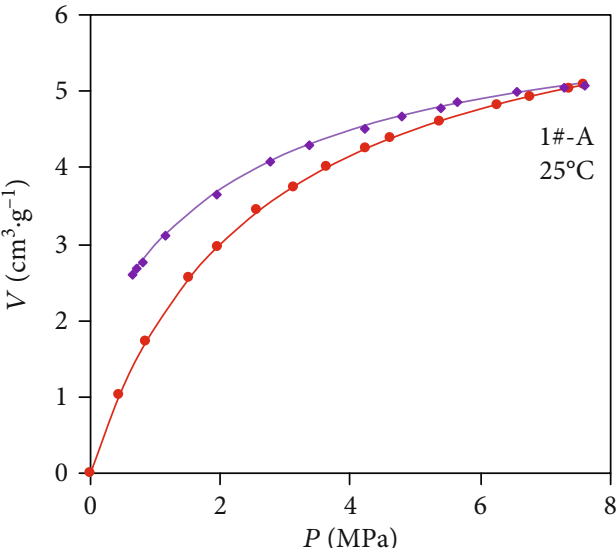

- Fit the adsorption curve

- Adsorption data

- Desorption data

Fit the desorption curve

(a)

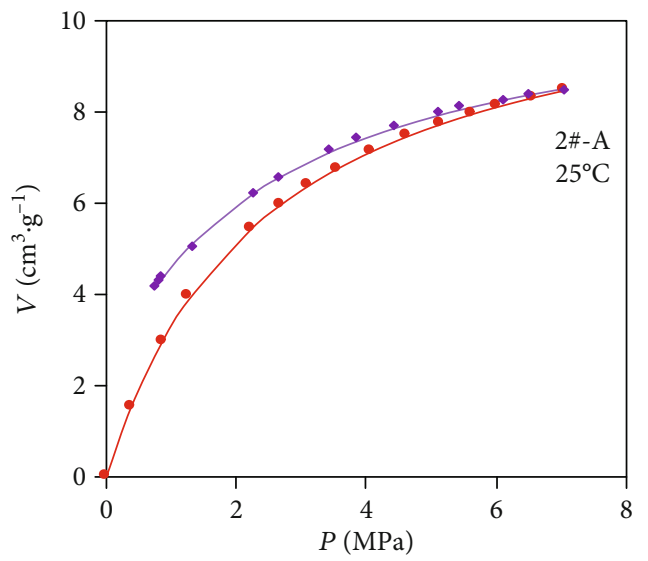

- Fit the adsorption curve

- Adsorption data

- Desorption data

— Fit the desorption curve

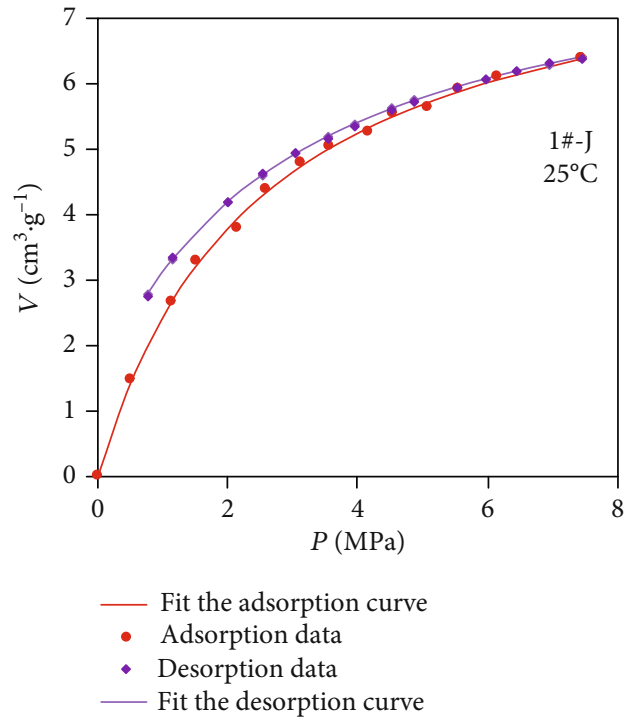

(b)

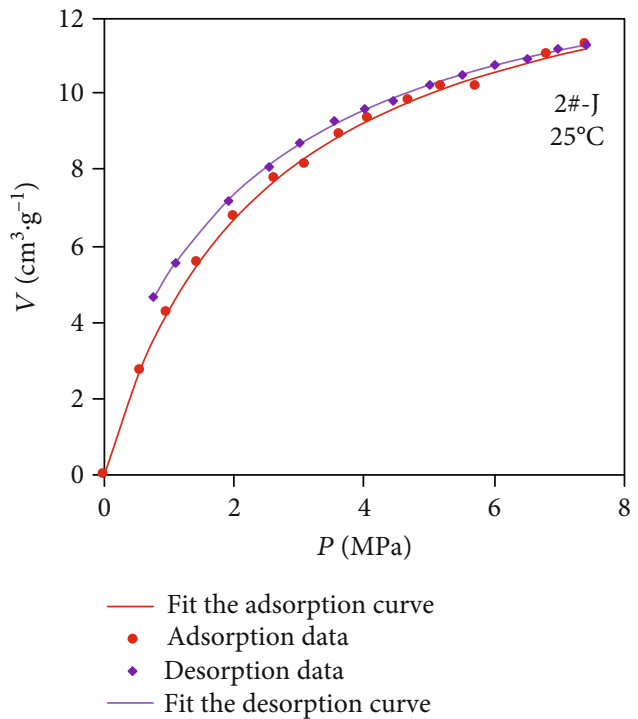

(d)

FIgURe 8: Continued. 

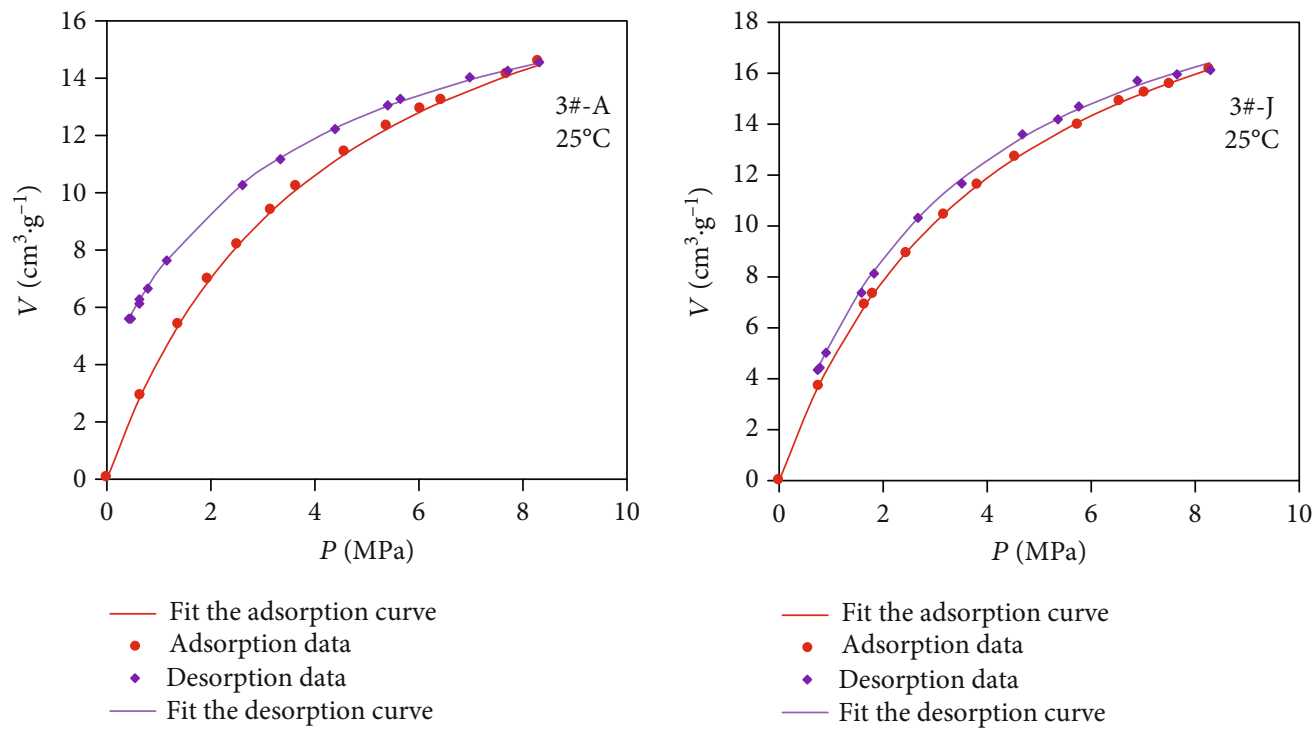

(e)

(f)

FigURE 8: Isothermal adsorption-desorption curves of vitrain and durain.

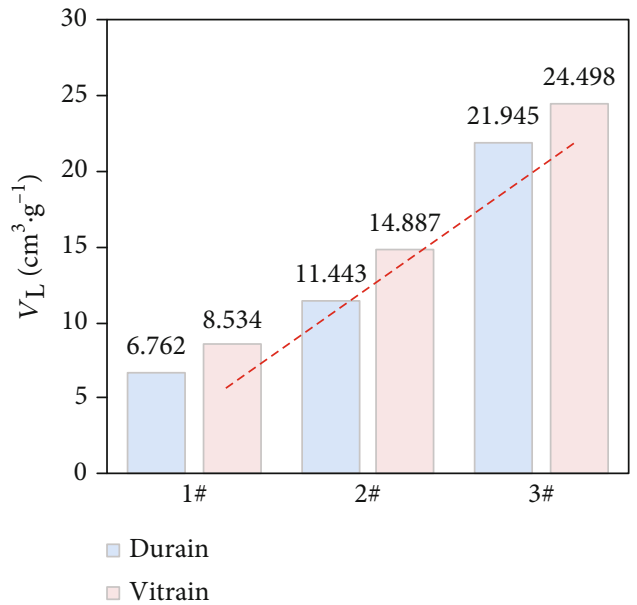

(a)

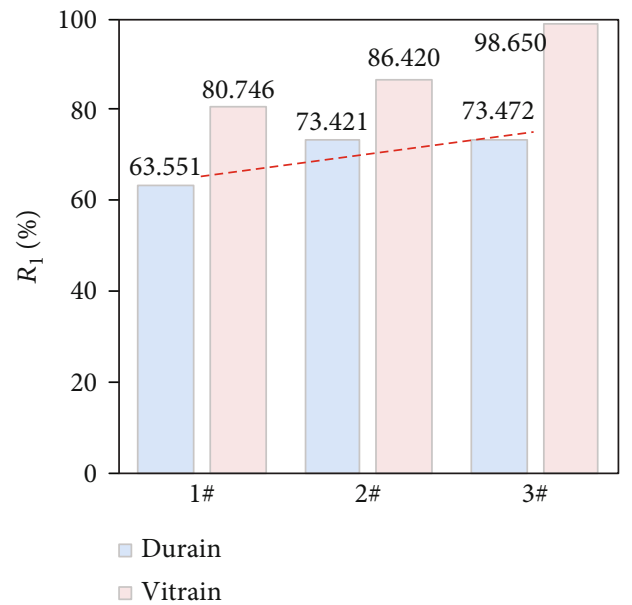

(b)

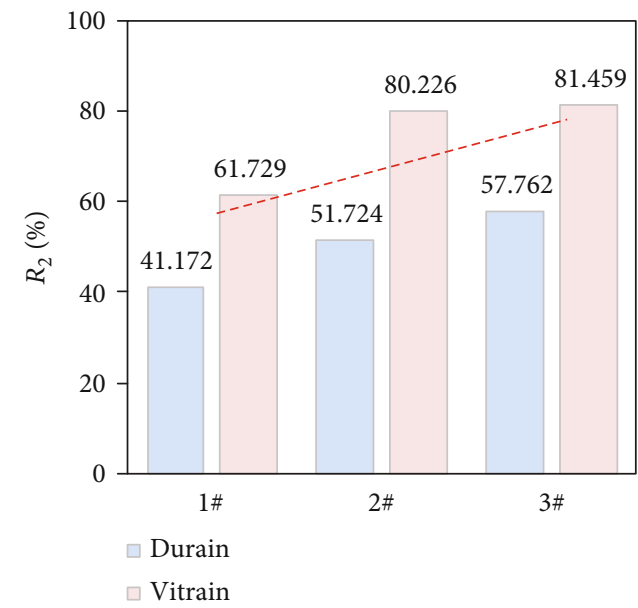

(c)

FIGURE 9: Adsorption and desorption parameters for vitrain and durain. 


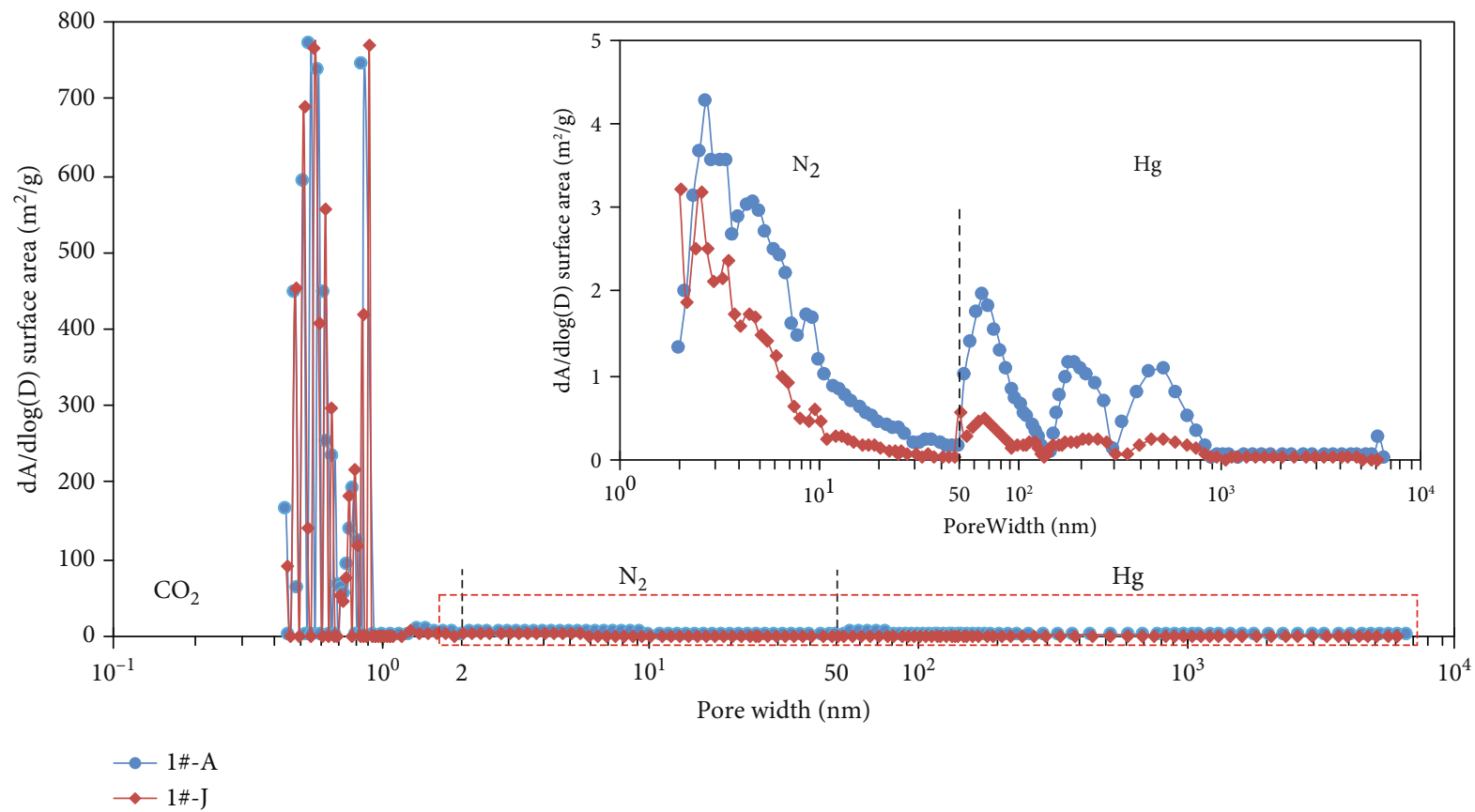

(a)

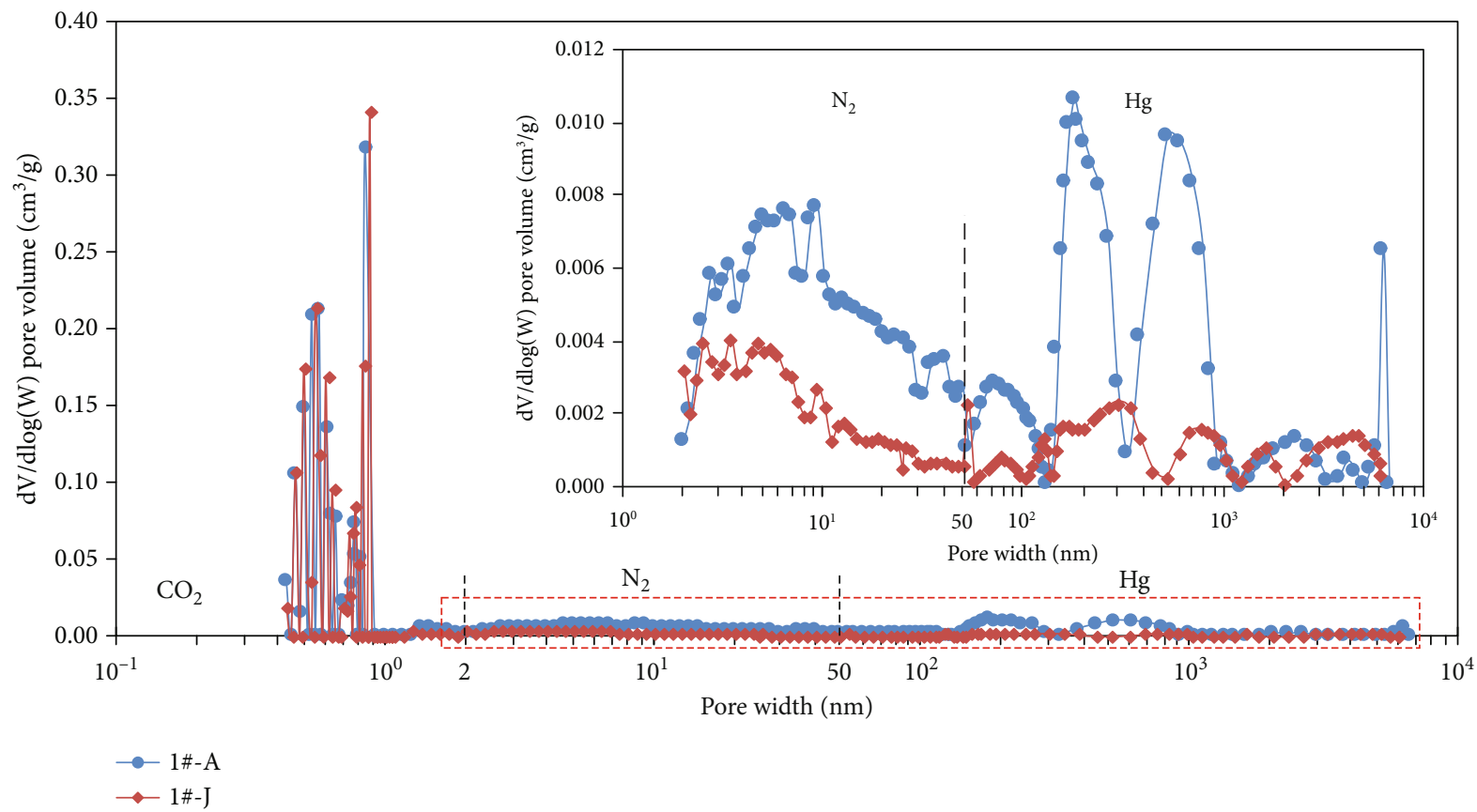

(b)

Figure 10: Correlation between the SSA, PV, and pore width of vitrain and durain. (a) Correlation between dA/dlog(D) and pore width; (b) Correlation between $\mathrm{dV} / \mathrm{d} \log (\mathrm{D})$ and pore width.

pressure $(\mathrm{P} / \mathrm{P} 0>0.01)$. The samples $1 \#-\mathrm{A}$ and $1 \#-\mathrm{J}, 2 \#-\mathrm{A}$, and $2 \#-J$ have smaller differences in isothermal curves, indicating that the samples have similar pore characteristics. The samples 3\#-A and 3 \#-J have significantly different isotherm curves, suggesting that they have significantly different pore characteristics. Ref. [25] believes that the DFT model is more suitable to reflect the adsorption and filling of gas in micropores, so it is used to analyze micropores. The $\mathrm{CO}_{2}$
$\mathrm{dV} / \mathrm{d}(\log \mathrm{W})$ and $\mathrm{dA} / \mathrm{d}(\log \mathrm{W})$ curves of the six samples (Figure 7) suggest that the samples have a multimodal PSD in the micropores and PSD of 0.4-0.9 nm.

3.5. $\mathrm{CH}_{4}$ Isothermal Adsorption. Langmuir monolayer adsorption model is widely used for adsorption of gas in coal $[26,27]$. GAI-100 isothermal adsorption analyzer was used to simulate the original temperature of coal seams (Figure 8). 


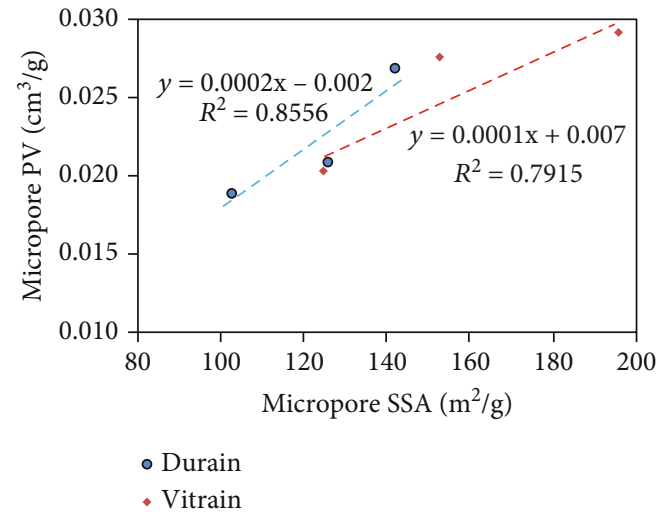

(a)

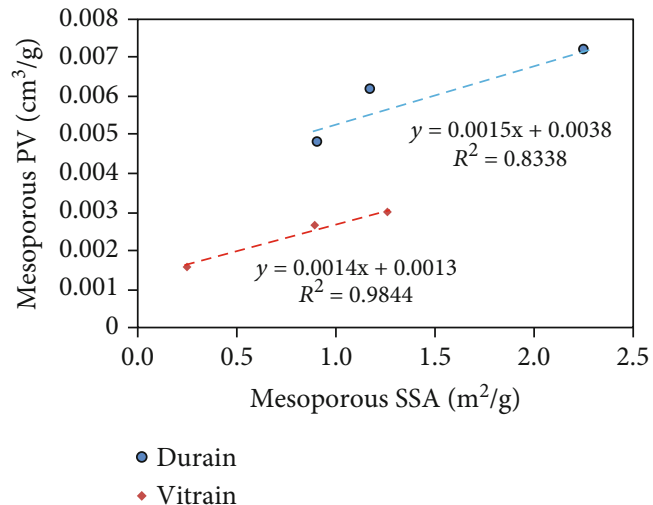

(b)

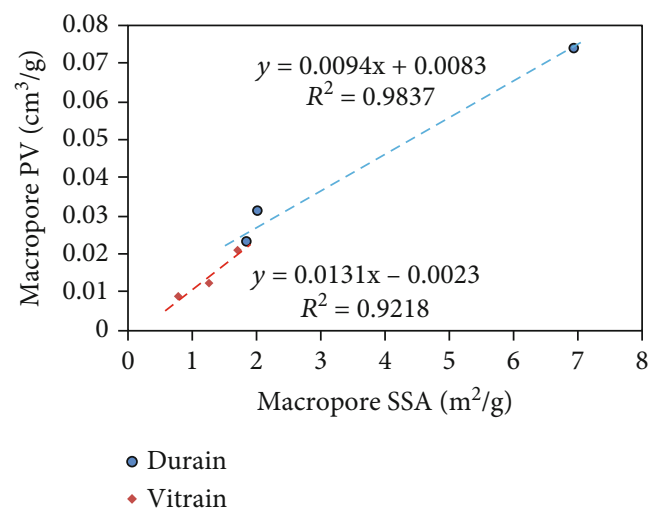

(c)

FIgURE 11: Correlation between the SSA and PV of vitrain and durain. (a) Micropore; (b) mesopore; (c) macropore.

Although the methane adsorption of coal conforms to the Langmuir Equation, the desorption process is delayed and not completely reversible [28]. The relation between adsorption capacity of coal and gas pressure can be displayed by the Langmuir Equation:

$$
V=\frac{V_{L} P}{P_{L}+P},
$$

where $V$ represents the adsorption capacity at the pressure $P$, $\mathrm{cm}^{3} \cdot \mathrm{g} ; P$ represents adsorption pressure, $\mathrm{MPa} ; V_{L}$ is the Langmuir volume, representing the maximum volume that can be adsorbed at infinite pressure, $\mathrm{cm}^{3} / \mathrm{g}$; and $P_{L}$ is Langmuir pressure, at which the adsorbed volume is half the Langmuir volume, $\mathrm{MPa}$.

Weibull model was used to fit the desorption curve. However, it is found that Equation (4) has a better fitting effect, and the parameters initially have physical significance [29]. In this paper, Equation (4) was used for desorption data fitting:

$$
V=\frac{V_{L} P}{P_{L}+P}+C .
$$

Therefore, the theoretical desorption rate $\left(R_{1}\right)$ and recovery rate $\left(R_{2}\right)$ can be calculated according to Equations
(5) and (6), respectively:

$$
\begin{aligned}
& R_{1}=\frac{V_{L}-C}{V_{L}} \times 100 \%=\left(1-\frac{C}{V_{L}}\right) \times 100 \%, \\
& R_{2}=\frac{V_{L}-C_{\text {des }}}{V_{L}} \times 100 \%=\left(1-\frac{C_{\text {des }}}{V_{L}}\right) \times 100 \%,
\end{aligned}
$$

where $C$ is residual adsorption at scarcity pressure, which is fitted by Equation (4), and $C_{\mathrm{des}}$ is residual adsorbance at abandonment pressure. According to the methane production experiences from the United States, the abandonment pressure is around $0.7 \mathrm{MPa}$, and it is impossible to produce the coalbed methane in the pressure drop stage [30]. The isothermal adsorption and desorption experiments of vitrains and durains were conducted at $25^{\circ}$, respectively. The adsorption and desorption curves are shown in Figure 8 , and the relevant calculation parameters are shown in Table S5. The results show that vitrain has greater $V_{L}, R_{1}$, and $R_{2}$ than durain (Figure 9), and vitrain and durain have almost identical $P_{L}$ in the adsorption process.

\section{Discussion}

4.1. Characteristics of PSD, PV, and SSA. MIP and LPA are restricted for PSD, PV, and SSA. For instance, MIP is only suitable for macropores $(>50 \mathrm{~nm})$ due to the test pressure 


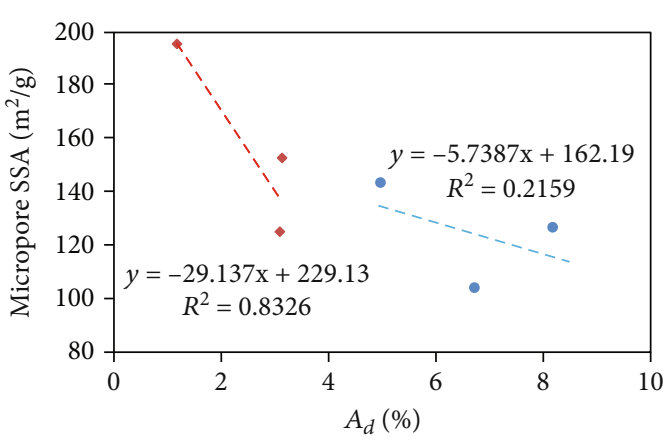

- Durain

- Vitrain

(a)

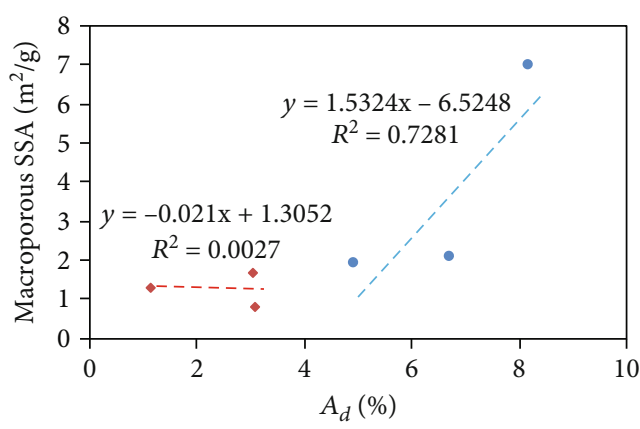

- Durain

- Vitrain

(c)

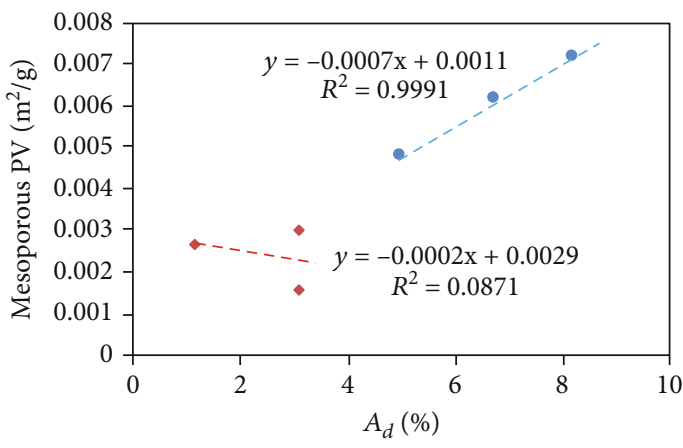

- Durain

- Vitrain

(e)

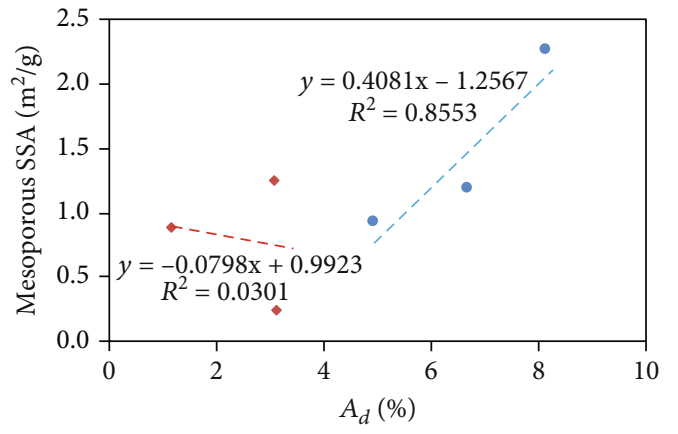

- Durain

- Vitrain

(b)

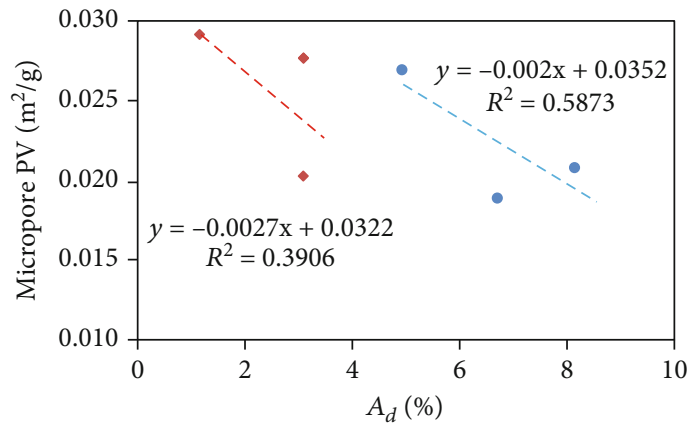

- Durain

- Vitrain

(d)

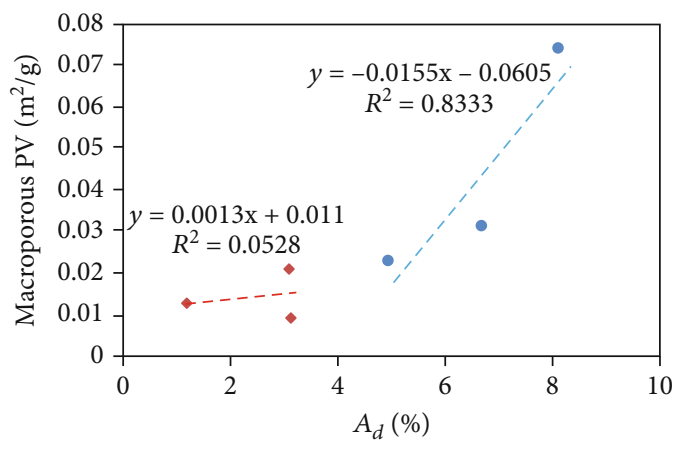

- Durain

- Vitrain

(f)

FIGURE 12: Relationship between ash content of vitrain and durain and micropore (a, d), mesopore (b, e), and macropore (c, f).

restriction; low-pressure $\mathrm{N}_{2}$ adsorption is effective for mesopores $(2-50 \mathrm{~nm})$, and $\mathrm{CO}_{2}$ adsorption is precise at the micropore level $(0.35-2 \mathrm{~nm})[25,31]$. The experimental method combining MIP, $\mathrm{N}_{2}$ adsorption, and $\mathrm{CO}_{2}$ adsorption indicates the distribution characteristics of different pore sizes. More comprehensive information on pore size is obtained by integrating the advantages of various experimental methods. In summary, the curve splicing method was used to connect the three analysis results at $2 \mathrm{~nm}$ and $50 \mathrm{~nm}$, respectively, to describe the change characteristics of SSA and PV within the PSD of the sample.
In this paper, the correlation between pore width and SSA and PV was obtained from the curves of dA/dlog(D) vs. pore width and $d V / d \log (D)$ vs. pore width (Figure 10). According to the curve distribution characteristics in Figure 9, the SSA percentage ranks in the descending sequence: micropore $(93.19 \sim 99.33 \%)>$ macropore $(0.51 \sim$ $5.15 \%)>$ mesopore $(0.16 \sim 2.26 \%) \quad$ (Table S6). The PV percentage does not change significantly.

Figure 11 shows the relationship between SSA and PV. For vitrain and durain, a positive correlation is observed between SSA and PV of micropores (Figure 11(a)), SSA and 

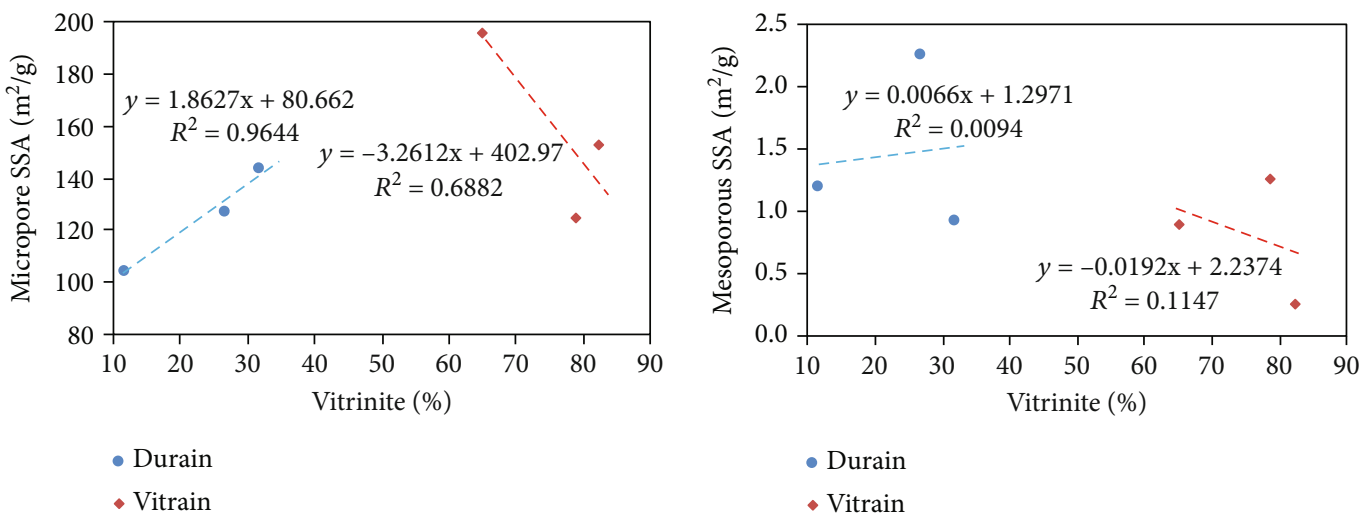

(a)

(b)

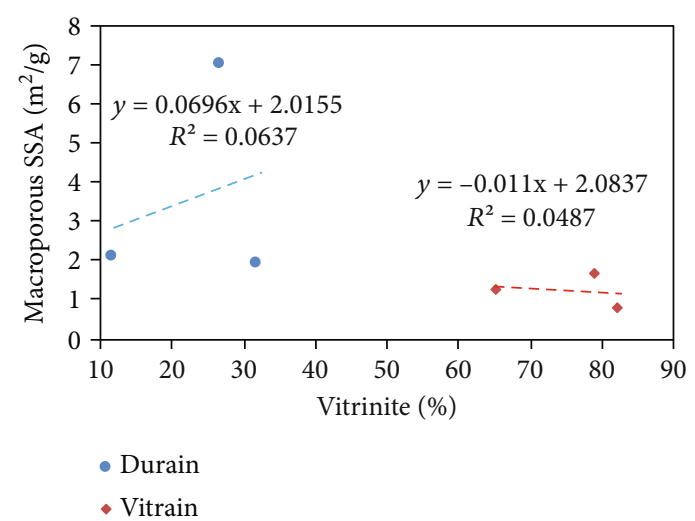

(c)

FIGURE 13: Correlation between vitrinite content and SSA. (a) Micropore; (b) mesopore; (c) macropore.

PV of mesopore (Figure 11(b)), and SSA and PV of macropore (Figure 11(c)). Vitrain and durain have a positive correlation between SSA and PV in their micropores, mesopores, and macropores, with correlation coefficients $\left(R^{2}\right)$ of $0.7915,0.9844$, and 0.9218 , respectively, and $0.8556,0.8338$, and 0.9837 , respectively.

\subsection{Effect of Ash Content on Pore Structure Characteristics.} The effects of ash content on SSA and PV are rather complicated $[15,32,33]$. The curves of ash content $\left(A_{d}\right)$ versus micropore, mesopore, and macropore are shown in Figure 12 . For vitrain and durain, the ash content $\left(A_{d}\right)$ has a negative linear correlation with SSA of micropore. Durain has higher correlation coefficient $\left(R^{2}=0.8326\right)$ than vitrain $\left(R^{2}=0.2159\right)$. In spite of no correlation between ash content and SSA $\left(R^{2}=0.0301\right)$ of mesopore and SSA $\left(R^{2}=0.0027\right)$ of macropore in durain, the ash content has a positive linear correlation with SSA $\left(R^{2}=0.8553\right)$ of mesopore and SSA $\left(R^{2}=0.7281\right)$ of macropore in vitrain. Ref. [15] argued that ash content affected both SSA and PV, and the increase of ash content was obviously related to the SSA of the micropores. Ref. [34] believed that the ash content was not significantly correlated with PV $\left(R^{2}=0.34\right)$ of mesopore, but positively correlated with SSA $\left(R^{2}=0.68\right)$ of mesopore. Ref. [32] found that the micropore characteristics were closely associated with the ash content, and a negative correlation between ash content and micropore characteristics was observed. For vitrain and durain, Ref. [33] also confirmed that the ash content had a distinct correlation with PV and SSA. Their results showed that the ash content influenced SSA of micropores in vitrain more greatly than mesoporous and macroporous coals and SSA and PV of mesopore and macropore in durain more greatly than microporous coal. The results accord with the previous understanding and extend the effects of the ash content on the pore structure of the coals with different lithotypes.

4.3. Effect of Maceral Composition on Pore Structure Characteristics. The effects of maceral composition on SSA and PV are complicated $[15,32,35,36]$. The effects of maceral composition on PV and SSA of vitrain and durain were studied by the curves of their respective properties vs. vitrinite, exinite, and inertinite contents (Figures 13-15).

Figure 13 shows the correlation between vitrinite group and SSA. For durain, the vitrinite group is positively correlated with SSA, and its content is positively correlated with SSA of micropore, not mesopore and macropore. The correlation coefficient $\left(R^{2}\right)$ between vitrinite group content and SSA of micropore is 0.9644 , mesopore 0.0094 , and macropore 0.0637 . For vitrain, the vitrinite group content is negatively correlated with SSA, and the correlation coefficient $\left(R^{2}=0.6882\right)$ between vitrinite group content and SSA of 


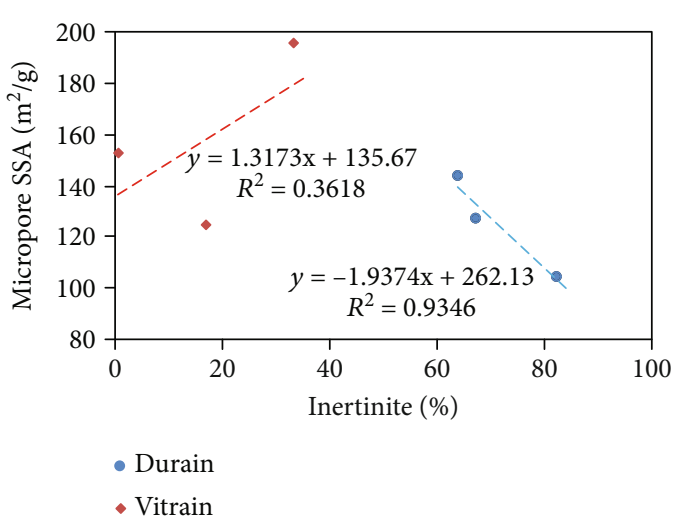

(a)

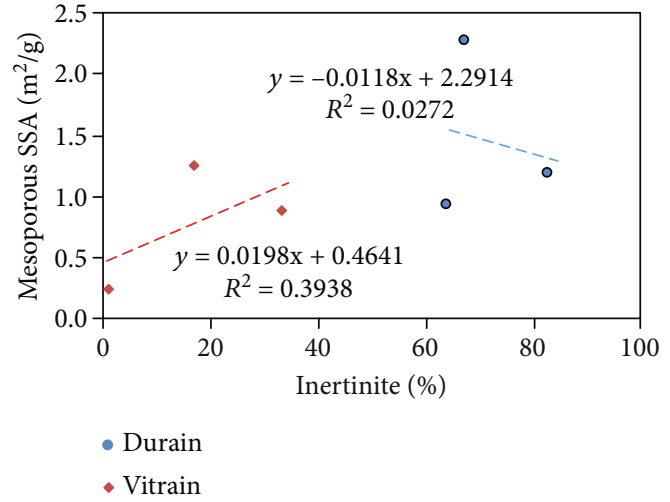

(b)

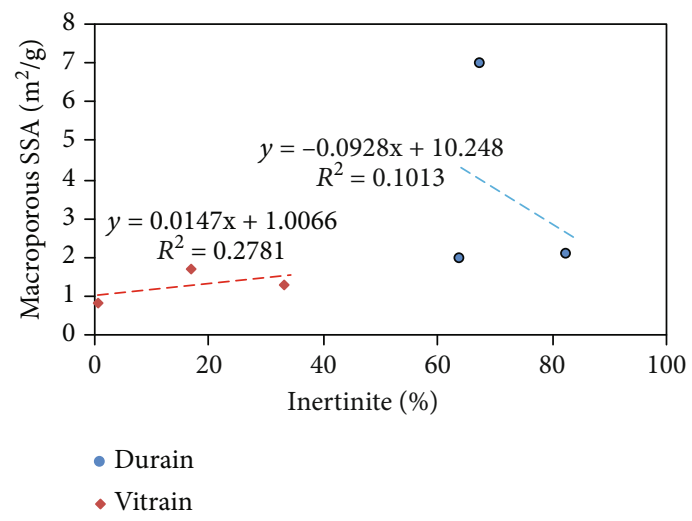

(c)

FIgURE 14: Correlation between inertinite content and SSA. (a) Micropore; (b) mesopore; (c) macropore.

micropore is significantly higher than that of mesopore $\left(R^{2}=0.1147\right)$ and macropore $\left(R^{2}=0.0487\right)$.

The correlation between the inertinite group and SSA is shown in Figure 14. For vitrain, there is a positive correlation between inertinite content and SSA. For durain, there is a negative correlation between inertinite content and SSA. For durain, the correlation between the inertinite group content and the SSA of micropore $\left(R^{2}=0.9346\right)$ is significantly greater than that of mesopore $\left(R^{2}=0.0272\right)$ and macropore $\left(R^{2}=0.1013\right)$, indicating that the inertinite group content has a significant effect on the SSA of micropore. For vitrain, the correlation coefficient between inertinite group content and SSA is not greater than 0.3938 , meaning a weak correlation.

For vitrain and durain, the exinite group content is negatively correlated with SSA (Figure 15). For micropore, durain has a stronger correlation between exinite content and SSA than vitrain. For micropore, the correlation coefficient between exinite group content and SSA in durain is 0.9874 and 0.0599 , respectively (Figure 15(a)), implying that the exinite influences the SSA in durain more greatly than the SSA in vitrain. For mesopore and macropore, the correlation between exinite group content and SSA in vitrain is 0.775 and 0.6651 , respectively, much higher than that in durain (Figures 15(b) and 15(c)), suggesting that the exinite influences the SSA in vitrain more greatly than the SSA in durain.
The correlation between maceral composition and SSA and PV in coal is different. Ref. [35] studied the SSA and PV of carboniferous bituminous coal in Zonguldak Basin and concluded that there was no obvious correlation between the maceral composition and SSA and PV. According to the research of Ref. [15], the effects of maceral composition on SSA and PV are too complicated to be quantified unless pure macerals are available for analysis. Ref. [32] used the ratio of vitrinite to inertinite (V/I) to represent the maceral composition, which showed a negative correlation with the mesopore characteristics and insignificant correlation with the micropore characteristics. The research result of Ref. [36] shows that there is a strong correlation between SSA, PV, and maceral composition, i.e., vitrinite, liptinite, and inertinite have strongly positive, weakly positive, and strong negative correlation with SSA and $\mathrm{PV}$, respectively. In this study, the correlation between maceral composition and SSA and PV in vitrain and durain was compared. The results show that the maceral composition of durain has a negative correlation with SSA and greatly influences the SSA of micropore. For vitrain, there is an insignificantly positive correlation between vitrinite content and SSA and a negative correlation between exinite and inertinite content and SSA, and the SSA of mesopore and macropore is significantly affected by the exinite and inertinite content. 


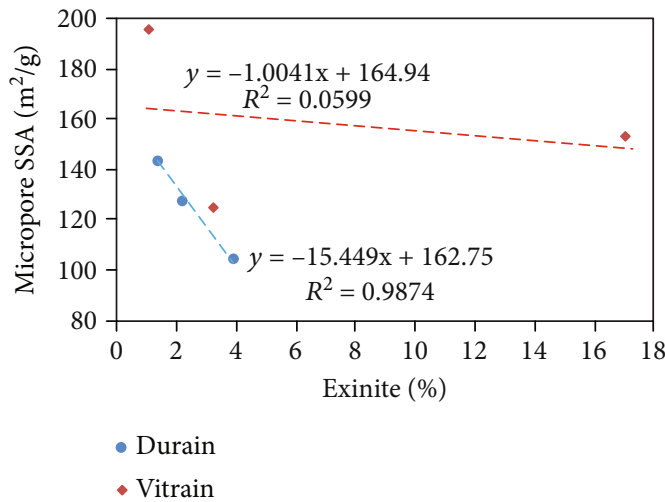

(a)

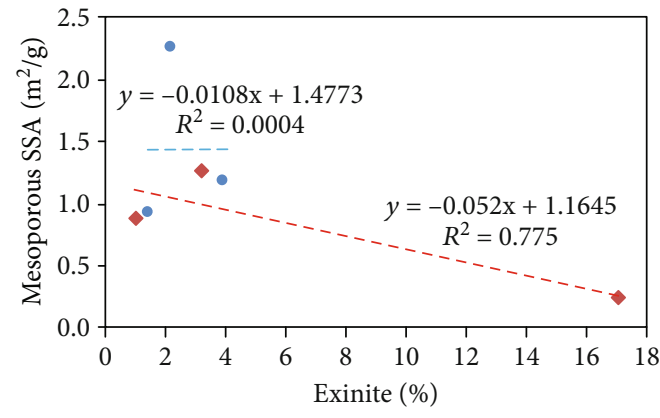

- Durain

- Vitrain

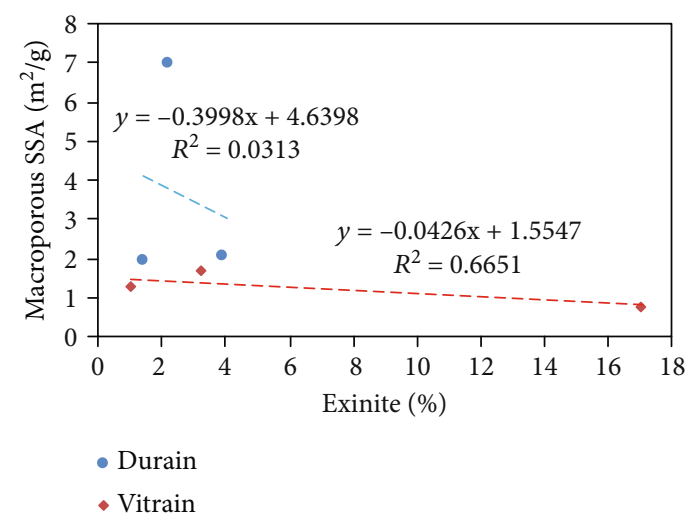

(c)

FIGURE 15: Correlation between exinite content and SSA. (a) Micropore; (b) mesopore; (c) macropore.

4.4. Analysis of the Factors Controlling the Adsorption Capacity, Desorption Rate, and Recovery Ratio. Researchers used different methods to study the factors affecting the adsorption of methane from coal. The methane adsorption capacity of coal mainly depends on the chemical composition, physical and chemical structure, deterioration degree, and moisture of coal and is also affected by external factors, such as temperature and pressure $[5,14,37,38]$. There are also many studies on the methane-from-coal desorption law and influencing factors.

In this paper, the microscopic pore structure of vitrain and durain which are different in lithotype was analyzed, and the methane adsorption and desorption characteristics were studied by isothermal adsorption and desorption experiments. The experimental and calculated data are shown in Table S5. The results show that vitrain has greater methane adsorption capacity, desorption rate, and recovery ratio than durain. Ref. [39] studied the effects of lithofacies composition on gas adsorption and found that bright coal has much higher adsorption than dark coal at the same coal rank, consistent with this study.

The relationship between microscopic pore structure and methane adsorption and desorption parameters is shown in Figure 16. There is a negative correlation between SSA and methane adsorption capacity, desorption rate, and recovery ratio of durain. The correlation coefficient $\left(R^{2}\right)$ between SSA and methane adsorption is greater than 0.36. Vitrain has a relatively complicated relationship between SSA and methane adsorption capacity, desorption rate, and recovery ratio, i.e., the SSA of micropore is positively correlated with methane adsorption capacity, desorption rate, and recovery ratio (Figures 16(a), 16(d), and 16(h)), while the SSA of mesopore and macropore is weakly negatively correlated with methane adsorption capacity, desorption rate, and recovery ratio. The methane adsorption capacity, desorption rate, and recovery ratio are mainly controlled by the micropore of vitrain and by the mesopore and macropore of durain. The weaker closure of the micropores of the coal reservoir leads to higher transmission efficiency of pressure difference, and thereby higher gas desorption volume and higher desorption efficiency on the inner surfaces of the micropores [40-42]. This is why vitrain, in which the micropores develop, desorbs methane more easily than durain.

\section{Conclusions}

(1) As low-rank coals, vitrain and durain lithotypes from coalbeds in Yan'an Formation of Huanglong Jurassic Coalfield (Guojiahe mine, Dafosi Mine, and Huangling 2 Mine) were studied by analyzing their chemical composition and pore structure. Vitrain and 


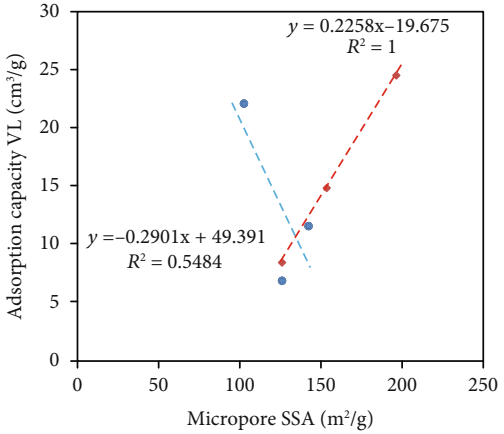

(a)

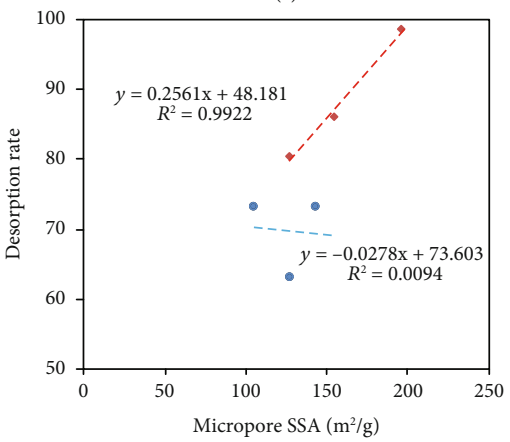

(d)

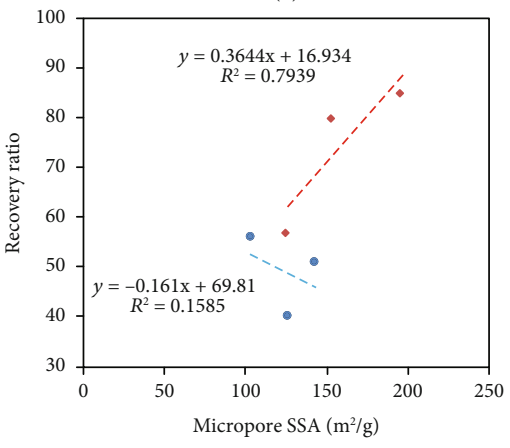

- Durain

- Vitrain

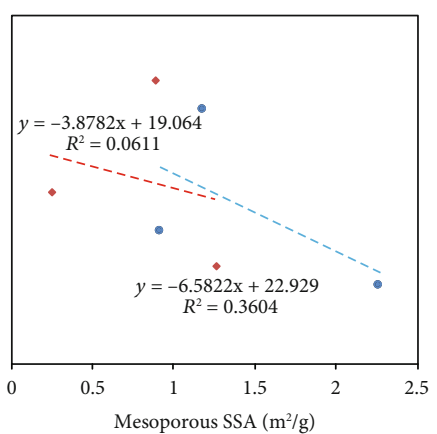

(b)

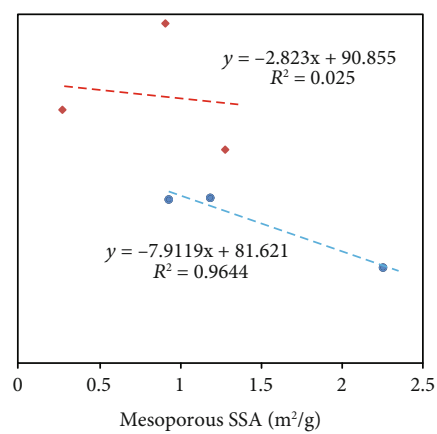

(e)

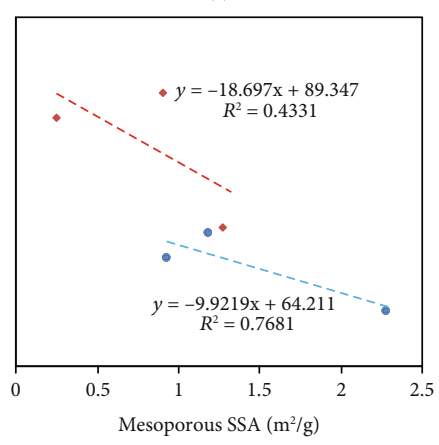

(h)

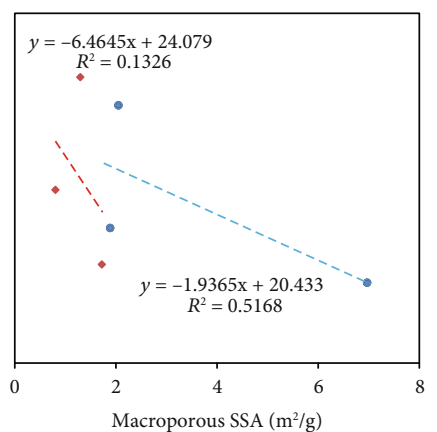

(c)

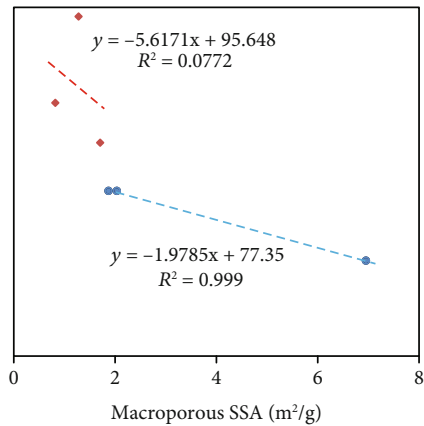

(f)

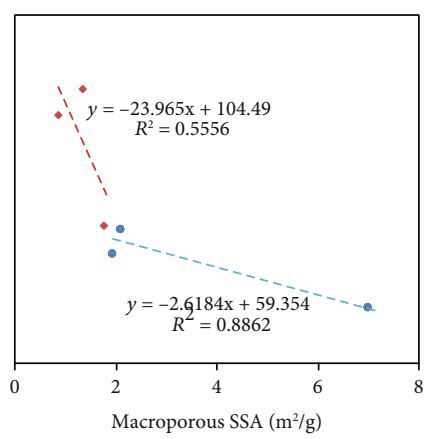

(i)

FIGURE 16: Correlation between (a) adsorption capacity and SSA, (b) between adsorption rate and SSA, and (c) between recovery ratio and SSA.

durain are quite different in chemical composition. Vitrain has higher moisture content, volatile yield, and vitrinite group content than durain. Vitrain and durain mainly contain vitrinite group and inertinite, respectively

(2) The pores of coal samples are mainly micropores $(<2 \mathrm{~nm})$, followed by mesopores $(2-50 \mathrm{~nm})$. The SSA of coal mainly distributes in micropores, and the PV mainly distributes in micropores and macropores $(>50 \mathrm{~nm})$. Vitrain has larger SSA and PV and smaller SSA and PV of mesopore and macropore than durain. The SSA and PV have a strong positive correlation

(3) The influence of ash content on the amount of SSA and PV is rather complicated. The ash content of vitrain and durain is negatively correlated with the SSA and PV. Vitrain has a stronger correlation between ash content and SSA of micropore and weaker correlation between ash content and PV of micropore than durain. For durain, the ash content influences the SSA and PV of mesopore and macropore more greatly than those of micropore

(4) The maceral composition is closely related to SSA, especially the SSA of micropores. The SSA has a positive and negative correlation with the vitrinite content of durain and vitrain, respectively. For durain, the inertinite and exinite contents are negatively correlated with the SSA. For vitrain, the SSA is negatively and positively correlated with exinite content and inertinite content, respectively

(5) Vitrain has better methane adsorption capacity, desorption rate, and recovery ratio than durain, and these parameters are significantly affected by the micropore characteristics 


\section{Data Availability}

The experimental data used to support the findings of this study are included within the manuscript and the supplementary materials.

\section{Conflicts of Interest}

The authors declare that there are no conflicts of interest regarding the publication of this paper.

\section{Acknowledgments}

This investigation is financially supported by the Natural Science Basic Research Program of Shaanxi (2020JQ1000), the China Postdoctoral Research Foundation (2018M633642XB), the Shaanxi Postdoctoral Research Foundation (2018BSHQYXMZZ08), and the Open Fund of Key Laboratory of Coal Resources Exploration and Comprehensive Utilization, Ministry of Land and Resources (KF2019-1 and KF2020-2).

\section{Supplementary Materials}

Table S1: experimental analysis analyzer and purpose of the vitrain and durain. Table S2: proximate analysis and maceral analysis of vitrain and durain. Table S3: PV and SSA distribution during liquid $\mathrm{N}_{2}$ adsorption. Table S4: micropore size, volume, and SSA during $\mathrm{CO}_{2}$ adsorption. Table S5: fitting parameters of the adsorption and desorption data. Table S6: pore parameters of full pore diameter section of vitrain and durain. (Supplementary Materials)

\section{References}

[1] G. R. Chalmers, R. M. Bustin, and I. M. Power, "Characterization of gas shale pore systems by porosimetry, pycnometry, surface area, and field emission scanning electron microscopy/transmission electron microscopy image analyses: examples from the Barnett, Woodford, Haynesville, Marcellus, and Doig unitsCharacterization of gas shale pore systems," AAPG Bulletin, vol. 96, no. 6, pp. 1099-1119, 2012.

[2] D. Ren, D. Zhou, D. Liu, F. Dong, S. Ma, and H. Huang, "Formation mechanism of the upper Triassic Yanchang formation tight sandstone reservoir in Ordos Basin-take Chang 6 reservoir in Jiyuan oil field as an example," Journal of Petroleum Science and Engineering, vol. 178, pp. 497-505, 2019.

[3] D. Liu, W. Sun, D. Ren, and C. Li, "Quartz cement origins and impact on storage performance in Permian Upper Shihezi Formation tight sandstone reservoirs in the northern Ordos Basin, China," Journal of Petroleum Science and Engineering, vol. 178, pp. 485-496, 2019.

[4] Z. Liu, Z. Zhang, S. K. Choi, and Y. Lu, "Surface properties and pore structure of anthracite, bituminous coal and lignite," Energies, vol. 11, no. 6, p. 1502, 2018.

[5] R. M. Bustin, A. M. Bustin, A. Cui, D. Ross, and V. M. Pathi, Eds., "Impact of shale properties on pore structure and storage characteristics," in SPE Shale Gas Production Conference, Fort Worth, TX, USA, November 2008.

[6] M. Thommes, K. Kaneko, A. V. Neimark et al., "Physisorption of gases, with special reference to the evaluation of surface area and pore size distribution (IUPAC Technical Report)," Pure and Applied Chemistry, vol. 87, no. 9-10, pp. 1051-1069, 2015.

[7] B. Nie, X. Liu, L. Yang, J. Meng, and X. Li, "Pore structure characterization of different rank coals using gas adsorption and scanning electron microscopy," Fuel, vol. 158, pp. 908 917, 2015.

[8] D. Liu, W. Sun, and D. Ren, "Experimental investigation of pore structure and movable fluid traits in tight sandstone," Processes, vol. 7, no. 3, p. 149, 2019.

[9] D. Liu, Z. Gu, R. Liang et al., "Impacts of pore-throat system on fractal characterization of tight sandstones," Geofluids, vol. 2020, 17 pages, 2020.

[10] Y. Yao, D. Liu, Y. Che, D. Tang, S. Tang, and W. Huang, "Petrophysical characterization of coals by low-field nuclear magnetic resonance (NMR)," Fuel, vol. 89, no. 7, pp. 13711380, 2010.

[11] Y. Yao and D. Liu, "Comparison of low-field NMR and mercury intrusion porosimetry in characterizing pore size distributions of coals," Fuel, vol. 95, pp. 152-158, 2012.

[12] A. P. Radlinski, M. Mastalerz, A. L. Hinde et al., "Application of SAXS and SANS in evaluation of porosity, pore size distribution and surface area of coal," International Journal of Coal Geology, vol. 59, no. 3-4, pp. 245-271, 2004.

[13] J. Kim, D. Kim, W. Lee, Y. Lee, and H. Kim, "Impact of total organic carbon and specific surface area on the adsorption capacity in Horn River shale," Journal of Petroleum Science and Engineering., vol. 149, pp. 331-339, 2017.

[14] C. R. Clarkson and R. M. Bustin, "Binary gas adsorption/desorption isotherms: effect of moisture and coal composition upon carbon dioxide selectivity over methane," International Journal of Coal Geology, vol. 42, no. 4, pp. 241-271, 2000.

[15] M. Mastalerz, A. Drobniak, D. Strąpoć, W. S. Acosta, and J. Rupp, "Variations in pore characteristics in high volatile bituminous coals: implications for coal bed gas content," International Journal of Coal Geology, vol. 76, no. 3, pp. 205-216, 2008.

[16] M. Mastalerz, A. Goodman, and D. Chirdon, "Coal lithotypes before, during, and after exposure to $\mathrm{CO} 2$ : insights from direct Fourier transform infrared investigation," Energy \& Fuels, vol. 26, no. 6, pp. 3586-3591, 2012.

[17] L. Drake, "Pore-size distribution in porous materials," Industrial \& Engineering Chemistry, vol. 41, no. 4, pp. 780-785, 1949.

[18] U. Kuila and M. Prasad, "Specific surface area and pore-size distribution in clays and shales," Geophysical Prospecting, vol. 61, no. 2, pp. 341-362, 2013.

[19] S. Yu, J. Bo, and L. Jie-gang, "Nanopore structural characteristics and their impact on methane adsorption and diffusion in low to medium tectonically deformed coals: case study in the Huaibei coal field," Energy \& Fuels, vol. 31, no. 7, pp. 67116723, 2017.

[20] M. Schmitt, C. P. Fernandes, J. A. B. da Cunha Neto, F. G. Wolf, and V. S. S. dos Santos, "Characterization of pore systems in seal rocks using nitrogen gas adsorption combined with mercury injection capillary pressure techniques," Marine and Petroleum Geology, vol. 39, no. 1, pp. 138-149, 2013.

[21] A. Gil, A. Massinon, and P. Grange, "Analysis and comparison of the microporosity in Al-, Zr- and Ti-pillared clays," Microporous Materials, vol. 4, no. 5, pp. 369-378, 1995.

[22] L. Qi, X. Tang, Z. Wang, and X. Peng, "Pore characterization of different types of coal from coal and gas outburst disaster sites using low temperature nitrogen adsorption approach," 
International Journal of Mining Science and Technology, vol. 27, no. 2, pp. 371-377, 2017.

[23] Y. Wang, Y. Zhu, S. Chen, and W. Li, "Characteristics of the nanoscale pore structure in Northwestern Hunan shale gas reservoirs using field emission scanning electron microscopy, high-pressure mercury intrusion, and gas adsorption," Energy \& Fuels, vol. 28, no. 2, pp. 945-955, 2014.

[24] D. M. Ruthven, Principles of Adsorption and Adsorption Processes, John Wiley \& Sons, 1984.

[25] J. Jiang, W. Yang, Y. Cheng, K. Zhao, and S. Zheng, "Pore structure characterization of coal particles via MIP, N2 and $\mathrm{CO} 2$ adsorption: effect of coalification on nanopores evolution," Powder Technology, vol. 354, pp. 136-148, 2019.

[26] I. Gray, "Reservoir engineering in coal seams: part 1-the physical process of gas storage and movement in coal seams," SPE Reservoir Engineering., vol. 2, no. 1, pp. 28-34, 2013.

[27] M. Mavor, L. Owen, and T. Pratt, Eds., "Measurement and evaluation of coal sorption isotherm data," in SPE Annual Technical Conference and Exhibition, New Orleans, LA, USA, September 1990.

[28] Z. Suian, Y. Jianping, T. Shuheng, M. Dongmin, and H. Yongzhong, "Theoretical analysis of coal-methane adsorption/desorption mechanism and its reversibility experimental study," Natural Gas Industry, vol. 25, no. 1, pp. 44-46, 2005.

[29] D.-M. Ma, S.-A. Zhang, and Y.-B. Lin, "Isothermal adsorption and desorption experiment of coal and experimental results accuracy fitting," Journal of China Coal Society, vol. 36, no. 3, pp. 477-480, 2011.

[30] Z. Zhang, Y. Qin, G. X. Wang, and X. Fu, "Numerical description of coalbed methane desorption stages based on isothermal adsorption experiment," Science China Earth Sciences, vol. 56, no. 6, pp. 1029-1036, 2013.

[31] Y. Yuan and R. Rezaee, "Comparative porosity and pore structure assessment in shales: measurement techniques, influencing factors and implications for reservoir characterization," Energies, vol. 12, no. 11, article 2094, 2019.

[32] S. Hou, X. Wang, X. Wang, Y. Yuan, S. Pan, and X. Wang, "Pore structure characterization of low volatile bituminous coals with different particle size and tectonic deformation using low pressure gas adsorption," International Journal of Coal Geology, vol. 183, pp. 1-13, 2017.

[33] Z. Wang, Y. Cheng, Y. Qi, R. Wang, L. Wang, and J. Jiang, "Experimental study of pore structure and fractal characteristics of pulverized intact coal and tectonic coal by low temperature nitrogen adsorption," Powder Technology, vol. 350, pp. 15-25, 2019.

[34] F. Jiang, D. Chen, Z. Wang et al., "Pore characteristic analysis of a lacustrine shale: a case study in the Ordos Basin, NW China," Marine and Petroleum Geology, vol. 73, pp. 554-571, 2016.

[35] G. Gürdal and M. N. Yalçın, "Pore volume and surface area of the Carboniferous coals from the Zonguldak basin (NW Turkey) and their variations with rank and maceral composition," International Journal of Coal Geology, vol. 48, no. 1-2, pp. 133144, 2001.

[36] J. Teng, M. Mastalerz, and L. Hampton, "Maceral controls on porosity characteristics of lithotypes of Pennsylvanian high volatile bituminous coal: example from the Illinois Basin," International Journal of Coal Geology, vol. 172, pp. 80-94, 2017.
[37] J. I. Joubert, C. T. Grein, and D. Bienstock, "Sorption of methane in moist coal," Fuel, vol. 52, no. 3, pp. 181-185, 1973.

[38] P. Weniger, W. Kalkreuth, A. Busch, and B. M. Krooss, "Highpressure methane and carbon dioxide sorption on coal and shale samples from the Paraná Basin, Brazil," International Journal of Coal Geology, vol. 84, no. 3-4, pp. 190-205, 2010.

[39] M. Mastalerz, H. Gluskoter, and J. Rupp, "Carbon dioxide and methane sorption in high volatile bituminous coals from Indiana, USA," International Journal of Coal Geology, vol. 60, no. 1, pp. 43-55, 2004.

[40] D. Ma, Q. Li, Q. He, and C. Wang, "Pore characteristics of vitrain and durain in low rank coal area," Journal of Power and Energy Engineering, vol. 5, no. 11, pp. 10-20, 2017.

[41] G. Sheng, Y. Su, and W. Wang, "A new fractal approach for describing induced-fracture porosity/permeability/compressibility in stimulated unconventional reservoirs," Journal of Petroleum Science and Engineering, vol. 179, pp. 855-866, 2019.

[42] G. Sheng, H. Zhao, Y. Su et al., "An analytical model to couple gas storage and transport capacity in organic matter with noncircular pores," Fuel, vol. 268, article 117288, 2020. 